IZA DP No. 5554

Pensions, Household Saving, and Welfare:

A Dynamic Analysis

David M. Blau

March 2011 


\title{
Pensions, Household Saving, and Welfare: A Dynamic Analysis
}

\author{
David M. Blau \\ Ohio State University \\ and IZA
}

\section{Discussion Paper No. 5554 \\ March 2011}

IZA

P.O. Box 7240

53072 Bonn

Germany

Phone: $+49-228-3894-0$

Fax: +49-228-3894-180

E-mail: iza@iza.org

Any opinions expressed here are those of the author(s) and not those of IZA. Research published in this series may include views on policy, but the institute itself takes no institutional policy positions.

The Institute for the Study of Labor (IZA) in Bonn is a local and virtual international research center and a place of communication between science, politics and business. IZA is an independent nonprofit organization supported by Deutsche Post Foundation. The center is associated with the University of Bonn and offers a stimulating research environment through its international network, workshops and conferences, data service, project support, research visits and doctoral program. IZA engages in (i) original and internationally competitive research in all fields of labor economics, (ii) development of policy concepts, and (iii) dissemination of research results and concepts to the interested public.

IZA Discussion Papers often represent preliminary work and are circulated to encourage discussion. Citation of such a paper should account for its provisional character. A revised version may be available directly from the author. 


\section{ABSTRACT}

\section{Pensions, Household Saving, and Welfare: A Dynamic Analysis}

Empirical analyses of the effects of public and private pensions on household saving impose strong assumptions in order to obtain a tractable empirical model: fixed retirement and pension claiming ages, no borrowing constraint, little or no uncertainty, and no institutional restrictions on pension claiming. I specify a richer version of the life cycle model that relaxes these assumptions. I calibrate, solve, and simulate the model and use the results to study three issues: (1) How much household wealth is crowded out by pensions? (2) Can linear regression analysis accurately estimate the magnitude of crowdout when the assumptions used in the empirical analysis are invalid? (3) How valuable are pensions to households? Simulation results indicate that private pensions in the US crowd out less than $\$ 0.15$ of household saving per dollar of pension wealth. Crowdout by Social Security is larger at $\$ 0.33$, but far smaller than the one-for-one offset predicted by a stylized version of the life cycle model. Regression estimates of crowdout using the simulated data are systematically larger than simulated crowdout, indicating that empirical estimates of crowdout are quite sensitive to the assumptions required in order to use the regression approach. The welfare analysis implies that, conditional on Social Security, DB pensions are worth less than their expected present discounted value to households, while DC pensions are worth more than their dollar value. In the absence of a private pension, Social Security is worth $50 \%$ more to households than its expected dollar value.

JEL Classification: J26

Keywords: pensions, saving, retirement

Corresponding author:

David M. Blau

Department of Economics

Ohio State University

445 Arps Hall

1945 N. High St.

Columbus, OH 43210-1172

USA

E-mail: blau.12@osu.edu

\footnotetext{
* Financial support from grant R01-AG02199 from the National Institute on Aging is gratefully acknowledged. I appreciate helpful comments by Cristian Bartolucci, Luc Behaghel, Andrew Clark, Robert Clark, Robert Willis, and participants at the September 2009 conference on "Saving for Old Age in Financial Turmoil," CeRP, Collegio Carlo Alberto, Torino; the 2009 Population Association of America Annual Meetings; and seminar participants at Australian National University, Paris School of Economics, the Federal Reserve Bank of New York, Yale University, Boston College, and IndianaPurdue University at Indianapolis. Helpful advice from Gary Engelhardt, Alan Gustman, and Tom Steinmeier on pensions, and from Wilbert van der Klaauw on computational issues is also appreciated. None of the above are in any way responsible for the contents. Comments are welcome.
} 


\section{Introduction}

The effect of pensions on household saving is a question of long standing interest to economists and policymakers. The issue has become especially salient in recent years, for two reasons. First, financial imbalances in unfunded public pension systems around the world have led to significant benefit cuts, and rapid population aging makes further cuts virtually inevitable. Second, there has been a major shift in the United States in recent years in employer-sponsored pensions away from Defined Benefit plans toward Defined Contribution plans. ${ }^{1}$ The retirement and saving incentives of these two types of pensions are very different. Understanding how household saving behavior is affected by benefit cuts in public pensions and the changing composition of private pensions is crucial for optimal pension design and welfare analysis of pensions.

Economic reasoning based on the life cycle model predicts that households respond to the implicit savings accumulated in their public and private pension plans by saving less in other forms. Thus pensions displace or "crowd out” household saving. A large literature has used linear or quantile regression analysis to estimate the magnitude of such crowdout. The studies in this literature vary along many dimensions: time period, country, type of pension analyzed, age

${ }^{1}$ Defined Benefit (DB) pension plans provide employees with an annuity, the amount of which is a function of age, length of service, and pre-retirement earnings. DB plans typically provide a strong financial incentive to remain with the employer until reaching a benchmark age and/or years of service, and relatively little incentive to remain thereafter. Defined Contribution (DC) plans specify the amount or percent of the employee's pretax earnings contributed to her pension account by the employee and employer. The assets in the account are allocated by the employee among the investment options available in the plan. The returns and capital gains accrue to the account tax free. The funds in the account become available to the employee upon retirement from the firm. The retiree can take receipt of the account balance as a lump sum payment, leave it to accumulate without further contributions, or roll it over into a tax-sheltered Individual Retirement Account. 
range of households, type of data used, and source of identification. ${ }^{2}$

All of these studies do share one common feature, however: the empirical analysis is implicitly or explicitly based on a very simple stylized version of the life cycle model. The assumptions of the model include fixed retirement and pension claiming ages, a perfect capital market, little or no uncertainty, and no bequest motive. In this simple framework, analytic solutions for optimal consumption and wealth profiles can be derived. The model predicts onefor-one crowdout: an additional dollar of pension wealth (the present discounted value of future benefits) causes a one dollar increase in consumption expenditure, spread out over the remaining lifetime. The increased consumption is financed by holding one less dollar in non-pension wealth (Gale, 1998). The logic behind this prediction is straightforward. Consumption is the only good in the model, so there is nothing else, such as leisure or bequests, on which to spend the additional pension wealth. Saving for precautionary purposes is irrelevant if there is no uncertainty, so saving for retirement is the only motive for wealth accumulation. The assumption of a perfect capital market allows households to smooth consumption regardless of the timing of pension receipt. Under the assumptions of this model, one can compute a measure of pension wealth and use it as an explanatory variable in a regression model of household saving.

It has long been understood that intuition about crowdout may not hold in a more realistic setting. Feldstein (1974) pointed out that when the timing of retirement is a choice, the effect of Social Security wealth on private saving is ambiguous in sign (see also Crawford and Lilien, 1981). If an increase in pension wealth causes earlier retirement, then the additional saving

\footnotetext{
${ }^{2}$ Banerjee (2010) reviews the empirical literature. I briefly discuss results from the literature in Section 4.
} 
needed to finance consumption during a lengthier period of retirement could result in a net increase in saving. In the presence of a borrowing constraint, the effect of future pension benefits on current household saving depends on the liquidity of the pension and the degree of the constraint (Gale, 1998). Uncertainty about future earnings, asset returns, medical expenses, and length of life may induce precautionary savings which could affect the magnitude of pension crowdout. Other savings motives such as for bequests could also affect the extent of crowdout.

Despite awareness of these issues, empirical studies of the effects of pensions on household wealth not only base their intuition on the stylized version of the life cycle model, they also impose the assumptions of the model in the empirical analysis. The reason for this is that relaxing these assumptions leads to an intractable empirical model. It is very difficult to compute a measure of pension wealth if retirement age and pension claiming age are choice variables, or if there is a liquidity constraint, or if there is uncertainty about future earnings, medical expenses, etc. Furthermore, it is unlikely that pension wealth is a sufficient statistic for the effect of pensions on saving when pension plans are highly complex and heterogeneous. Empirical tractability is obviously important, but it is not clear how to interpret results estimated under such strong assumptions if the assumptions do not hold.

To illustrate this point more concretely, consider a regression model of saving in a population that is homogeneous in preferences, expectations, and endowments. Households differ ex ante only in their pension coverage, and pensions are heterogeneous. A typical regression model for non-pension assets $A_{i a}$ held by individual $i$ at age $a$ is

$$
A_{i a}=\beta_{0}+\beta_{1} P W_{i a}+\beta_{2} X_{i a}+\varepsilon_{\mathrm{ia}}
$$

where $P W_{i a}$ is pension wealth, $X_{i a}$ is a set of observed state variables, and $\varepsilon_{\mathrm{ia}}$ is a set of 
unobserved state variables. Pension wealth is the EPDV of future benefits, computed under assumptions such as little or no uncertainty, no liquidity constraint, and no choice over employment and pension claiming. $\beta_{1}$ measures crowdout, the extent to which implicit saving for retirement in one form, pensions, displaces direct saving for retirement.

In a world without uncertainty, liquidity constraints, and employment and pension claiming decisions, pension wealth is a sufficient statistic for the effects of pensions on household saving: other features such as the degree of illiquidity and restrictions on claiming age are irrelevant because their effects can be undone via the capital market. In the real world, the effects of such features cannot be neutralized so easily. Furthermore, pension benefits are highly nonlinear functions of state variables. Thus there is no reason to expect that pension wealth is a sufficient statistic for the effects of pensions on saving. For example, the effect on saving of a DB pension with a sharp discontinuity in the benefit formula at a particular age cannot be fully captured by a wealth equivalent measure. Some researchers attempt to overcome this problem in the related context of estimating the effects of pensions on retirement, by including an additional summary statistic such as the gain in pension wealth from delaying claiming by one period (e.g. Coile and Gruber, 2007). But a one period accrual measure cannot capture the effects of a discontinuity at a later age. Other more forward-looking measures have been proposed, but all are ad hoc, and there is no straightforward way to judge their ability to capture effects of pensions that are not picked up by pension wealth. The problem is further exacerbated by heterogeneity in pension plan features, making it quite difficult to compute summary statistics of sufficient generality to be broadly useful.

In this paper, I specify a richer version of the life cycle model that relaxes several of the 
key restrictions of the stylized model. The model incorporates employment and pension claiming decisions, a liquidity constraint, and various sources of uncertainty, as well as realistic tax treatment of pensions and institutional constraints on pension claiming. Some of the parameters of the model are estimated using data from the Health and Retirement Study (HRS), and others are calibrated to match employment patterns from age 51-75. The effects of public and private pensions on household saving and pension claiming decisions are analyzed by solving the model numerically and simulating behavior under alternative pension scenarios. The results are used to measure the "true" magnitude of crowdout by comparing simulated wealth profiles with and without pensions, all else equal. This approach to measuring crowdout relies on the assumption that the model is correct, as in the empirical literature, but the model I use here is much richer and more realistic than the standard model.

In order to compare the magnitude of crowdout implied by the model to the estimate one would derive from the usual empirical approach, I use the simulated data to estimate regression models of household wealth or saving like those found in the literature. Two measures of pension wealth are computed from the simulations: one that is consistent with the model from which the simulated data were generated, and another that, incorrectly, imposes the assumptions of the stylized model. The correct measure of pension wealth is derived as part of the numerical solution of the model, so it accounts for optimal employment and claiming choices as well as uncertainty and borrowing restrictions. Nevertheless, as discussed above, it cannot capture effects on saving caused by nonlinearities and discontinuities in pension incentives. The incorrect measure is computed in the usual way, assuming a perfect capital market, a fixed retirement age, and so forth. Comparing "true" crowdout derived directly from the simulations to 
regression estimates using the correct simulated measure of pension wealth, I can determine whether the linear regression approach provides an accurate approximation to the highly nonlinear process that generated the data. Comparing regression estimates using the correct and incorrect measures of pension wealth, I can determine the sensitivity of regression-based estimates to the usual strong assumptions required to calculate pension wealth.

The results indicate that crowdout of household saving by both DB and DC pensions in the rich life cycle model is less than $\$ 0.15$ per dollar of pension wealth. Crowdout by Social Security is larger at $\$ 0.33$ per dollar of Social Security wealth. Regression estimates of crowdout using the simulated data are larger than the "true" simulated magnitude of crowdout, especially for Social Security. This is the case for both the correct and incorrect measures of pension wealth, indicating that the main problems with the regression approach are the linearity assumption, and the assumption that pension wealth is a sufficient statistic for the impact of pensions on household saving. The magnitude of crowdout is quite sensitive to model specification. When employment and claiming decisions are eliminated from the model, crowdout increases to $-\$ 0.46$ for DB pensions and $-\$ 0.80$ for SS. When all sources of uncertainty are eliminated from the model, DC crowdout increases from -0.09 to $-\$ 0.59$. Eliminating the tax benefit of DC pensions causes a further increase in crowdout to $-\$ 0.87$. These results indicate that model specification matters: the strong assumptions of the stylized model are not innocuous.

To measure the value of pensions to households, I compute the compensating variation (CV) measure: the amount of additional initial wealth that would be required to compensate pension holders for the lifetime utility that would be lost if the pension was unavailable. This measure could be less than the associated measure of pension wealth, if, for example, individuals 
are relatively impatient or the liquidity constraint is binding. Alternatively, the annuities provided by DB pensions and SS could be worth more to households than their EPDV if there is significant risk aversion, substantial uncertainty about future income, or large tax benefits. The welfare calculations indicate that, conditional on the existence of Social Security, DB pensions are valued by households at about 50 cents per dollar of pension wealth. DC pensions are valued at $\$ 1.35$ per dollar in the DC pensions account. The difference may be explained by the tax advantage and relative liquidity of DC balances. For a household without an employer-provided pension, Social Security is valued at about 1.5 times its wealth equivalent value. These valuations are sensitive to the level of initial wealth with which the household is endowed.

Finally I use the model to simulate the impact on household saving of recent and future cuts in Social Security benefits. The findings indicate that large benefit cuts will induce moderately large increases in saving and retirement age, while the welfare losses are substantially less than proportional to the magnitude of the benefit cuts.

The following section of the paper describes the life cycle model used in the analysis, and illustrates the implications of the restrictions implied by the typical stylized version. Section 3 describes the data, parameter calibrations, and initial conditions. The simulation results are

discussed in section 4 . Section 5 briefly describes the results of counterfactual policy analyses, and conclusions are offered in section 6 .

\section{A Life Cycle Model of Saving, Employment, and Pension Claiming}

The model developed here characterizes the behavior of an unmarried individual from the middle (age 51) to the end of the life cycle, taking as given the individual's characteristics when 
first observed in middle age. ${ }^{3}$ The individual makes a categorical employment choice $j_{t}$ and a continuous consumption choice $c_{t}$ in period $t$, where consumption is defined as net of out-ofpocket medical expenditure. The employment choice set is: (0) non-employment, (1) a job with a new employer, and (2) the job with the period $t-1$ employer. The latter alternative is available only if the individual was employed in period $t-1$ and not laid off at the end of the period. A job offer from a new employer is assumed to be available in every period, but new jobs do not provide pension coverage. Allowing job switching is important because pensions are usually employer-specific, and it is often possible to leave the pension-providing employer, begin to collect the pension benefit, and work for another employer. The length of a period is one year. The last age to which the individual can survive is denoted $T$, and the last age in which employment is an option is $T^{*}<T$. In the analysis, $T=100$ and $T^{*}=75$. The employment choice is eliminated after age 75 in order to speed up solution of the model. This restriction is very rarely binding in practice.

If the individual is eligible for a retirement benefit from Social Security (Old Age and Survivors Insurance, abbreviated as SS) and has not yet claimed the benefit, he makes a claiming decision in period $t$. Employment and claiming are distinct decisions. An individual who chooses to leave a firm in which he is covered by a DC pension, or has previously left the firm and has not yet claimed the balance in the pension account, makes a claiming decision. The options are to allow the DC account balance to continue to accumulate tax free, or to claim the balance as a

\footnotetext{
${ }^{3}$ Starting in the middle of the life cycle has some disadvantages, as discussed below, but has the advantage of avoiding the need to model saving for children's education. Solving a version of the model for married couples is conceptually straightforward but very computation intensive. See van der Klaauw and Wolpin (2008) for an example.
} 
lump sum and transfer it into the non-pension account. ${ }^{4}$ There is no separate claiming decision for DB pensions: age and years enrolled at the time of exit fully determine whether the individual will receive a benefit and the benefit start date.

The logarithm of the hourly wage offer from employer $k$ ( $k=1$ for a new employer, $k=2$ for the previous-period employer) is given by $\ln \left(w_{k t}\right)=\beta_{1} a_{t}+\beta_{2} a_{t}^{2}+\beta_{3} x_{t}+\varepsilon_{k p}$, where $a_{t}$ is age in period $t, x_{t}$ is a set of other state variables, and $\varepsilon_{k t}$ is an iid normal shock. ${ }^{5}$ The logarithm of outof-pocket medical expenditure is determined as $\ln \left(m_{t}\right)=\beta_{4} a_{t}+\beta_{5} x_{t}+\varepsilon_{3}$, where $\varepsilon_{3 t}$ is an iid normal shock. The probability of death in period $t, \pi_{t}$, is a logit function of age and $x_{t}{ }^{6}{ }^{6}$ The probability that an employed individual is laid off at the end of period $t, \lambda_{t}$, is also a logit function of age and $x_{t}$.

An individual is eligible to claim his Social Security benefit if he has reached the Social

${ }^{4}$ There is a tax penalty of $10 \%$ of the account balance if the pension is claimed before age $591 / 2$ ( 60 in the model). The balance must be claimed no later than age 70 in the model, consistent with legal requirements. There is no installment payment option or annuity option in the model. The model does not incorporate Individual Retirement Accounts (IRAs), but the option to let the account balance continue to accumulate tax free after leaving the pensionproviding employer is equivalent to rolling over the balance into a tax sheltered IRA. Also, the model does not allow purchase of annuities in the private market.

${ }^{5}$ This wage process is stationary, unlike those assumed in some recent models (van der Klaauw and Wolpin, 2008, and Low, Meghir, and Pistaferri, 2010). Because of the discrete choices, the model cannot be expressed in terms of the wealth-income ratio (see Gourinchas and Parker, 2002). As a result, when wages are nonstationary, the state space includes scenarios with explosive growth in wealth. The assumption that the wage does not vary with work experience and job tenure at older ages is consistent with empirical evidence (see French, 2005, and Low et al., 2010, for example).

${ }^{6} \mathrm{Health}$ is not included in the model, and the possibility of becoming disabled and enrolling in the Social Security Disability Insurance program is also ignored. A previous version of the model incorporated these features, but they made little difference to the outcomes, so I dropped them for computational reasons and to focus on the elements of the model that are crucial for pensions. The model also excludes health insurance, for similar reasons. 
Security early retirement age (62). ${ }^{7}$ The benefit, $s_{t}$, is a real annuity determined by the function $s_{t}$ $=s\left(A I M E_{f e}, f e, E_{t}, a_{t}\right)$, where $A I M E_{f e}$ is Average Indexed Monthly Earnings, $f e$ is the age at which the individual claims the benefit (first entitles), $E_{t}=H_{t} w_{t}$ is annual earnings in period $t$, and $H_{t}$ is annual hours of work (0 or 2000). Age and current earnings matter because there is an earnings test at some ages. ${ }^{8}$

The nominal annuity provided by a DB pension plan, $b$, depends on age, years of enrollment in the plan, and earnings history at the date of exit from the pension-providing firm. The formula can be written in general as $b=b\left(E_{p}, a_{e}, y_{e}\right)$, where $E_{p}$ is a summary statistic for the worker's earnings history at the pension-providing firm (e.g., the average of the last five years), and $a_{e}$ and $y_{e}$ are age and years of enrollment in the plan at the time of exit. The DB benefit is nominal, so its real value at age $a_{t}$ depends on the inflation rate and years since the benefit began. There is no risk of default by the pension plan. It is computationally infeasible to allow both $E_{p}$ and $A I M E_{f e}$ to be state variables, so as in French (2005) I assume that $E_{p}=A I M E_{f e}$. The DB pension benefit must be taken no later than age 65, even if the individual has not yet retired from the pension job. ${ }^{9}$ The benefit formula depends on the specific pension plan in which the worker is enrolled. Below, I describe the source of the pension benefit formulas used in the analysis.

\footnotetext{
${ }^{7} \mathrm{I}$ assume that the individual has accumulated the minimum required quarters of coverage (40) by age 51 .

${ }^{8} A I M E$ is the average of the highest 35 years of covered earnings. Covered earnings are capped at a real value of $\$ 55,500$ in 1992 dollars. AIME is recalculated each period until the individual claims the benefit. The 1992 Social Security rules are used in the analysis, with one exception: the elimination of the earnings test for beneficiaries who have reached full retirement age, which took place in 2000, is assumed to apply throughout the analysis. See Social Security Administration (2010) for description of the benefit determination rules.

${ }^{9}$ This is consistent with regulations specified in the Employee Retirement Income Security Act (ERISA). See Purcell and Staman (2008, page 56).
} 
DC pension plans are characterized by the account balance and the employee and employer contribution rates. While employed at the pension-providing firm, the individual and the firm contribute specified fractions of the individual's pretax earnings to the pension account. These fractions are taken as given and fixed. If the individual remains with the pensionproviding firm at the beginning of period $t+1$ and has not reached age 70 , the account balance is given by $D_{t+1}=\left(D_{t}+E_{t}(w c+e c)\right)\left(1+r_{t+1}\right)$ where $w c$ and $e c$ are the worker and employer contribution rates, respectively, and $r_{t+1}$ is the rate of return on assets held at the beginning of period $t+1$. If the individual has left the firm but has not yet claimed the account balance, then $D_{t+1}=D_{t}\left(1+r_{t+1}\right)$. Borrowing from a DC pension account is not allowed..$^{10}$

The rate of return earned on assets held at the end of period $t, A_{t}^{*}$, is realized at the beginning of period $t+1$. The rate of return is determined by a mean-reverting stochastic process specified as $1+r_{t+1}=(1+\overline{\mathrm{r}}) \exp \left\{\theta_{\mathrm{t}+1}\right\}$, where $\overline{\mathrm{r}}$ is the mean rate of return, and $\theta_{\mathrm{t}}$ is an idiosyncratic individual-specific shock, distributed iid normal. Returns are defined to include capital gains, so $r_{t+1}<0$ corresponds to a capital loss. The rate of return is assumed to be the same for the DC pension account and the individual's other assets. ${ }^{11}$

${ }^{10}$ Previous simulation studies of the effects of pensions on savings have accounted for some of the features modeled here, but in a more limited way, and none have incorporated all of them. Scholz, Seshadri, and Khitatrakun (2006) approximate the benefits from DB plans as a function of job tenure and earnings in the last period before retirement. Engen, Gale, and Uccello (1999) use an estimated replacement rate to approximate a DB pension benefit. Laibson, Repetto, and Tobacman (1998) specify a DC plan with fixed contribution rates and a tax penalty for early withdrawal. These papers do not allow for choice of retirement age, but they do incorporate earnings and/or medical expenditure uncertainty and in some cases a liquidity constraint.

${ }^{11}$ The model does not include a portfolio allocation choice, so portfolio heterogeneity, which is the source of rate-of-return heterogeneity across individuals, is implicitly taken as given. 
The law of motion for assets held outside the DC account is $A_{t+1}=A_{t}^{*}\left(1+r_{t+1}\right)$. There is assumed to be a borrowing constraint $\left(A_{t} \geq 0 \forall t\right)$ and a consumption floor, $\overline{\mathrm{C}}>0$. The consumption floor is a simple approximation to income-and-asset-tested government programs such as Supplemental Security Income (SSI), Food Stamps, and Medicaid that allow individuals with no other sources of income to survive (Hubbard, Skinner, and Zeldes, 1995). If cash on hand is less than $\overline{\mathrm{C}}$, the government provides a grant sufficient to allow consumption of $\overline{\mathrm{C}} .^{12}$

Non-asset income net of out-of-pocket medical expenditure and taxes is

$$
I_{t}=E_{t}+b_{t}+s_{t}-m_{t}-\tau\left(E_{t}, b_{t}, s_{t}, m_{t}, A_{t}, a_{t}, w c\right),
$$

where $\tau$ includes federal income and payroll taxes, calculated using the rules in effect for 1992, and assuming the individual takes the standard deduction. The tax computation accounts for the tax-sheltered nature of the worker's contribution to the DC account, and for the rules governing taxation of Social Security benefits. Cash on hand at the beginning of period $t$ net of out-ofpocket medical expenditure and taxes is $A_{t}+I_{t}$, and assets carried forward to the next period, before the return is realized, are $A_{t}^{*}=A_{t}+I_{t}-c_{t}$, (unless the liquidity constraint is binding), where $c_{t}$ is non-medical consumption expenditure.

Utility is a function of consumption and employment. The functional form assumed here is isoelastic in consumption, separable in consumption and employment, and dynamic in employment:

$$
u_{t}=\left[c^{1-\alpha} /(1-\alpha)\right] \exp \left\{\varepsilon_{\mathrm{ct}}\right\}+\gamma_{1} W_{\mathrm{t}}+\gamma_{2}\left(1-W_{\mathrm{t}-1}\right) W_{\mathrm{t}}+\gamma_{3} W_{\mathrm{t}-1} N J_{\mathrm{t}}+H_{\mathrm{t}} \varepsilon_{\mathrm{lt}}
$$

where $W=1$ if employed, and zero otherwise, $N J=1$ if a new job is chosen, and zero otherwise,

${ }^{12} \mathrm{~A}$ large medical expenditure shock could cause end-of-period assets to be negative. In this case, the debt is forgiven before the beginning of the next period. 
and $\varepsilon_{\mathrm{ct}}$ and $\varepsilon_{\mathrm{lt}}$ are iid normal shocks to the utility from consumption and employment, respectively. ${ }^{13} \gamma_{1}$ is the disutility of employment, $\gamma_{2}$ is the additional disutility of employment if the individual was not employed in the previous period, and $\gamma_{3}$ is the additional disutility from changing jobs. The dynamic features of the utility function are important in order to avoid excessive churning in employment choices in response to transitory earnings and preference shocks. There is no bequest motive.

The individual's goal is to choose employment and consumption (and SS and DC claiming, if relevant) in period $t$ to maximize the EPDV of remaining lifetime utility, with discount factor $\delta$, subject to the constraints described above.

This model is very flexible with respect to pension crowdout. It is easy to imagine combinations of preferences and constraints that could result in very small crowdout. For example, strong preferences for leisure could induce early retirement and substantial private saving to finance consumption during retirement until eligibility for SS or the DB benefit, or until age 60, when the DC balance can be claimed without a tax penalty. The high rate of saving would occur even while the implicit pension value is growing rapidly. Strong risk aversion and inability to borrow against future income could drastically limit the extent of substitution of pensions for household saving. Alternatively, patient individuals will tend to accumulate a lot of saving for retirement, and are therefore unlikely to face either a binding liquidity constraint or the risk of bankruptcy. In this case, one form of saving for retirement might be a very good substitute for another.

\footnotetext{
${ }^{13}$ I assume that all of the disturbances in the model are independent. These include wage, medical expenditure, rate of return, utility, and, implicitly, layoff, and mortality shocks.
} 
The model has limitations as well. Pensions are complicated, and potentially important features have been omitted for computational reasons. Some of these features include choice over asset allocation and the form of benefit (lump sum, installments, or an annuity), borrowing against pensions, the risk of bankruptcy in DB pensions, and the enrollment decision. Some features of the environment that are relevant to saving and retirement behavior have been simplified considerably or omitted, in order to focus on pensions. These include SSDI, health, health insurance, nonstationarity in wages and medical expenditure, and time inconsistency and other nonstandard aspects of preferences and decision making. The results should be interpreted with these simplifications in mind.

The stylized version of the life cycle model that is the implicit or explicit basis for empirical analysis of pension crowdout is a special case of the model, with no uncertainty, no liquidity constraint, and no employment and claiming choices. This restricted version of the model can be solved analytically for household wealth in a given period prior to retirement (see Gale, 1998, and Attanasio and Rohwedder, 2003, for examples), and implies a regression specification of the form

$$
A_{t}=\beta_{1} X_{1 t}+\beta_{2} X_{2 t}+\beta_{3} X_{3 t}+\beta_{4} X_{4 t}+\beta_{5} X_{5 t}+\beta_{6} X_{6 t},
$$

where

$X_{1 t}=\left(1-\kappa_{\mathrm{t}}\right)\left[A_{t-1}{ }^{*}+D_{t-1}{ }^{*}\right]$ is lagged wealth plus the DC balance,

$\kappa_{\mathrm{t}}$ is an adjustment factor for remaining length of life, $X_{2 t}=\left(1-\kappa_{t}\right) E_{t}(1-w c-\tau)$ is take home pay, assuming a flat tax rate of $\tau$, $X_{3 t}=\kappa_{\mathrm{t}} P D V_{t}(E)$ is the PDV of future earnings, $X_{4 t}=\kappa_{t} P D V_{t}(b)$ is the PDV of future DB pension benefits, 


$$
\begin{aligned}
& X_{5 t}=\kappa_{t} P D V_{t}(s) \text { is the PDV of future Social Security benefits, and } \\
& X_{6 t}=D_{t} \text { is the DC balance in period } t .
\end{aligned}
$$

These restrictions deliver strong predictions: $\beta_{1}=\beta_{2}=1$, and $\beta_{3}=\beta_{4}=\beta_{5}=\beta_{6}=-1$. $\beta_{4}$, $\beta_{5}$, and $\beta_{6}$ are the coefficients that measure pension crowdout: the amount by which household wealth is reduced as a result of a one dollar increase in pension wealth. The virtue of this framework is its empirical tractability: under the assumptions of the model, the right hand side variables can be computed and the regression can be estimated with suitable data. I estimate regressions of this form using data simulated from the unrestricted model.

The model is formulated as a dynamic program (DP) and solved numerically by backward recursion on the value function, using Monte Carlo integration (with 50 draws from the distribution of the disturbances). There are as many as three continuous state variables, depending on age: household assets, the DC account balance, and AIME. There are also three discrete state variables at a given age: the age at which the individual first entitled to Social Security ( $f e$, set equal to zero if not yet entitled), years enrolled in the DB pension plan, and a categorical indicator of current pension status: whether covered, type of plan, and whether claimed. The model is solved for grids of values of the continuous state variables along with all feasible values of the discrete state variables at a given age. Multidimensional linear interpolation is used to approximate the expected value at $t$ of the period $t+1$ value function for each point in the period $t$ state space and each alternative in the period $t$ choice set. The pension wealth measures used in the regression analysis must also be approximated by interpolation. If the SS or DB benefit has not yet been claimed, its EPDV depends on future choices and realizations of shocks. The Appendix provides further details on solution issues. For a given set 
of discrete choices, optimal consumption is found by a grid search.

\section{Data, Calibration, and Simulation}

Data from the Health and Retirement Study (HRS) are used to estimate some parameters of the model, and to specify initial conditions. The HRS also provides benefit formulas for a sample of DB pension plans, which are used in solution and simulation. The HRS is a biennial longitudinal survey of a sample of U.S. households with individuals aged over 50 . The survey began in 1992 with a sample of individuals born from 1931 to 1941, and their spouses. Additional cohorts have been added periodically, but I use the original cohort because it has the most extensive data. Various subsamples are used to estimate the parameters of the wage, medical expenditure, layoff, and mortality functions, and to specify initial conditions.

A. Pensions. The HRS asks respondents who report being enrolled in a DB pension plan a substantial battery of questions about the plan, including the ages of early and normal retirement, expected benefits if the respondent was to leave the firm at the early and normal retirement ages, and the respondent's expected age of retirement and expected benefit at that age. Some studies have used this information to construct a measure of DB pension wealth (Chan and Stevens, 2008; Engelhardt and Kumar, 2011), but the information is not sufficient to calculate benefits for all possible retirement ages and earnings realizations. The HRS also obtained Summary Plan Description and other relevant information about the pension for a subsample of HRS respondents. The benefit formulas and other plan features derived from these documents were coded by HRS staff and made available in a data base, along with pension calculator software. The data and software allow one to compute the benefit to which an individual would be entitled 
under any combination of age, years of enrollment, and the salary profile. However, it was not feasible to integrate the pension calculator software with the model solution software. Instead, I use a very flexible plan-specific regression approximation of the benefit formulas in solution and simulation of the model. The approach is described in Appendix B. The pension data base also contains DC plans, but the only relevant DC plan characteristics in the model are contribution rates and the initial balance. Contribution rates are reported by respondents, and since DC plans often have multiple options for contribution rates, I use typical values reported by respondents. ${ }^{14}$

B. Calibration. The model was calibrated in three steps. First, the HRS data were used to estimate the parameters of the wage, medical expenditure, layoff, and mortality functions. ${ }^{15}$ The estimates are shown in the appendix in Tables A-1 and A-2, and several fitted values derived from the estimates are reported in the top panel of Table 1.

Second, the values of several other parameters were set arbitrarily. These include the coefficient of relative risk aversion $(\alpha=2.5)$, the consumption floor $(\overline{\mathrm{C}}=5 \mathrm{~K})$, the mean rate of return ( $\overline{\mathrm{r}}=.03)$, and the rate of time preference $(\delta=.03)$. The second panel of Table 1 shows these and the values of other arbitrarily chosen parameters. All monetary amounts are expressed in thousands of 1992 dollars. The sensitivity of the results to alternative values of these parameters

\footnotetext{
${ }^{14}$ See Gustman, Steinmeier, and Tabatabai (2010) for extensive description of pensions in the HRS.

${ }^{15}$ The log wage and log out-of-pocket medical expenditure functions are specified as linear models and estimated by OLS. The notes to Tables A-1 and A-2 provide details on the estimates. The estimated mean squared error from these regressions could be used as measures of the log variances of the wage and expenditure shocks. However, the estimated mean squared errors in both models implied excessively large variances. This is probably due to unobserved heterogeneity, as the unexplained variation includes cross-person differences as well as withinperson variation. These variances were therefore set arbitrarily.
} 
is discussed below.

The remaining parameters were calibrated so as to generate reasonable life cycle employment patterns. This was an informal process without a specific criterion for "reasonable." The disutility of employment parameters ( $\gamma$ 's) and the variances of the preference shocks were chosen in this manner. The parameter values for the baseline specification of the model are shown in the last panel of Table 1.

C. Simulation. Simulations of the model compare three pension scenarios: (1) no pension, (2) a DB pension, and (3) a DC pension. In all three cases the household is eligible for Social Security as well. A fourth scenario assumes no Social Security (and no payroll tax) as well as no pensions. This hypothetical scenario is used to evaluate the extent of crowd out by Social Security. The simulations use an arbitrarily chosen DB pension plan selected from the HRS pension provider data base. ${ }^{16}$ Results with alternative plans are reported as part of the sensitivity analysis. DC plans are characterized by the employer and employee contribution rates. ${ }^{17}$ These are set to typical values: .06 for the worker and .03 for the firm. I simulate 300 life cycles from age 51 to 100 for each pension and Social Security scenario, and average the results across simulations for each scenario. In the simulations individuals face mortality risk, but for ease of interpretation I assume that no deaths actually occur.

${ }^{16}$ Each DB pension plan has a unique benefit formula, so the model must be solved for each plan used in the analysis. I attempted to develop a value function approximation approach similar to the one used by van der Klaauw and Wolpin (2008) that would be flexible enough to encompass the formulas of a wide variety of plans. The formulas are so heterogeneous that this proved impossible.

${ }^{17}$ Another relevant feature of a DC plan is the set of investment options available in the plan. As described above, I assume that assets in the DC account balance earn the same mean return as assets held directly by the household, so this feature of DC plans is not considered here. 
D. Initial Conditions. The model is solved and simulated for an unmarried white man with a high school education, born in 1937, and age 51 in the first period of the simulation. The individual is assumed to be employed at the beginning of the first period. In the DB pension simulations, the individual is assumed to have enrolled in the plan at age 30. Other initial conditions were generated from the subsample of single white men in the HRS with a high school education who were employed at ages 51-53 with earnings of at least \$10K in 1991. These include the mean AIME,${ }^{18}$ the median value of assets at age 51 , and in the DC pension scenario, the median DC balance at age 51. Table 2 summarizes the initial conditions.

\section{Results}

\section{A. Model Fit}

Figures A1-A3 in the Appendix show simulated employment patterns from the model and actual employment patterns from the HRS data. The HRS sample includes men born from 19311941 who were employed full time in the first survey wave in 1992. The model fits the employment patterns up to the early 60s quite well, and captures the rapid decline in employment from the early 60s to the mid 70s. However, the model predicts a steeper decline than observed in the data, resulting in underprediction of employment from the mid 60s to the mid 70s. Recall that the preference specification is very simple, with no allowance for change in preferences with age or nonseparability of consumption and leisure. It is always possible to improve the fit of the model by adding more parameters to the preference specification. I avoid

\footnotetext{
${ }^{18}$ Data on the AIME are from administrative Social Security Earnings Records of respondents who gave permission for the HRS to obtain these records.
} 
this here because a tight fit to employment is not the goal of the analysis. The fact that the model captures the decline in employment associated with retirement solely through incentives makes it well suited for analysis of pension crowdout. It is also notable that the model captures the differences in employment patterns by pensions status, with DB pension holders retiring earliest, followed by DC pension holders, and non-pension holders.

\section{B. Basic Patterns}

Figures 1-3 show simulated life cycle patterns of employment, consumption, and assets for the four scenarios of interest: no pension (NP), DB pension, and DC pension, all with Social Security, and no-pension-no-Social Security (NPNSS). Employment declines rapidly beginning around age 55 in the DB scenario, and around age 60 in the NP and DC scenarios. In the NPNSS case, the employment decline starts later and is more gradual. Employment in the DB scenario falls more rapidly than in the other scenarios at ages 56-60; these are common early retirement ages in DB plans.

Consumption is expected to decline with age, because the effective rate of time preference (including both pure time preference [.03] and the mortality hazard rate [about .01 in the 50s and 60s]) exceeds the mean interest rate (.03). In Figure 2, this pattern is evident in the NPNSS scenario, but the decline does not begin until around age 70 in the NP and DC cases, and 84 in the DB case.

The wealth trajectory shown in Figure 3 follows the standard life cycle pattern, rising until retirement and then falling, with one exception. There is a dip in the DB asset trajectory in the early 60s followed by a rebound in the late 60s. This seemingly peculiar pattern is very robust, and is unique to the $\mathrm{DB}$ case. In the $\mathrm{DB}$ scenario, the individual will eventually receive 
two annuities, one real (SS) and the other nominal (DB). The DB benefit is claimed mainly at ages 59-61, while the SS benefit cannot be claimed until age 62, and in fact is mainly claimed at age 64 in the simulations. This pattern of staggered onset of annuity receipt seems to be the cause of the twin peaks in the asset profile. This pattern has little influence on the crowd out results discussed below, which are computed only for ages at which the pension benefit has not yet been claimed by most simulated individuals.

Figures 4 and 5 display simulated pension and Social Security claiming patterns. The DB benefit is claimed at age 59 in about half of all cases, and $80 \%$ have claimed by age 61 . This is consistent with the often abrupt changes in retirement incentives in DB plans. DC claiming is more gradual, consistent with the absence of retirement incentives at any specific ages. Social Security claiming is quite abrupt, with $60 \%$ of NP cases, $85 \%$ of DB cases, and 55\% of DC cases claiming at age 64. Social Security claiming is in fact highly concentrated, but not at age 64 . More than $40 \%$ of men and $50 \%$ of women claim at age 62 , the earliest possible age (see Song and Manchester, 2007). The most commonly cited explanation for the high frequency of claiming at age 62 is a liquidity constraint. As discussed below, the liquidity constraint is not usually binding in the simulations. And the pattern of abrupt claiming at age 64 is not a robust finding: The SS claiming age is rather sensitive to parameter values, and in many specifications the modal claiming age is 62 .

Summarizing the different scenarios, DB pensions increase the demand for leisure and consumption compared to the baseline NP scenario. The effects of DC plans on consumption and employment relative to the NP scenario are much smaller, due to the low initial balance (17K). In the absence of employer pensions, the effect of Social Security on demand for leisure is large 
(compare the NPNSS and NP scenarios in Figure 1), while optimal consumption is only slightly higher (Figure 2), until around age 80.

\section{Crowdout}

Figures 6-9 illustrate the crowdout patterns implied by the simulations. Figure 6 displays the life cycle crowdout pattern in the DB scenario, measured by the difference in mean household wealth between the DB and the NP scenarios. The dollar magnitude of crowdout in Figure 6 is equal to the vertical distance between the DB and NP asset profiles in Figure 3. Note that all households begin with the same initial wealth (41), so crowdout is zero by construction at the beginning of age 51. Figure 6 also shows the relevant pension wealth measure: the EPDV of future DB benefits, computed as part of the model solution. Assets in the DB case decline gradually relative to the NP case, with the difference reaching about $-25 \mathrm{~K}$ at age 60 . DB pension wealth rises from about $140 \mathrm{~K}$ at age 51 to almost $200 \mathrm{~K}$ at age 60 . Figure 9 shows the proportional crowdout profile, calculated as crowdout divided by DB pension wealth. Crowdout as a fraction of pension wealth starts at zero (by construction) and reaches about -0.20 by the early 60s. Figure 7 presents the dollar crowdout profile for the DC scenario, along with the DC balance. Crowdout by DC pensions is small, never exceeding $-10 \mathrm{~K}$, or -0.15 as a fraction of the DC balance. Figure 8 displays Social Security crowdout, measured by the vertical distance between the NPNSS and NP asset profiles in Figure 3. Crowdout by Social Security reaches about $-20 \mathrm{~K}$ at age 60 , or -0.20 as a proportion of SS wealth, and then grows substantially to $-80 \mathrm{~K}$ at age 70 , or -0.85 as a fraction of SS wealth.

The graphs are useful for illustrating crowdout patterns, and they make it clear that there is no single correct measure of crowdout. However, it is useful to summarize the magnitude of 
crowdout with a single number, as in the empirical literature. Initial assets are the same in all scenarios, so it is advisable to allow behavior to play out for at least a few years before measuring asset differences across scenarios. However, it is useful to measure crowdout at an age at which pensions and Social Security have not yet been claimed, both because this is the typical approach in the literature, and because crowdout behavior can be quite different in the asset decumulation phase. I arbitrarily chose to measure crowdout at the latest age at which at least $75 \%$ of simulated cases have not yet claimed the pension or Social Security benefit. As indicated in Figure 9, the crowdout estimates are not very sensitive to the specific age of measurement, within plus or minus two years. The first panel of Table 3 shows the results. The last age at which at least $75 \%$ of simulated individuals remain on the DB job is 58, and at age 58 DB crowdout is $-23 \mathrm{~K}$, or -0.13 as a proportion of $\mathrm{DB}$ pension wealth. The corresponding figures for DC and SS are $-5 \mathrm{~K}$ and $-42 \mathrm{~K}$, measured at ages 61 and 63 respectively, or -0.09 and -0.33 as a proportion of the relevant pension/SS wealth measure. Note that the age at which crowdout is measured is different in each case. If DC and SS crowdout are measured at the same age as DB crowdout (58), the result is about the same for DC (-.08) and smaller for SS (-0.15).

These crowdout measures are at the low end of empirical estimates in the literature, but are within the range of these estimates. ${ }^{19}$ Relatively small crowdout by DB pensions is plausible, since DB pensions are illiquid. But Social Security is illiquid as well, so it is somewhat

\footnotetext{
${ }^{19}$ Results from well known studies, along with some pertinent details in brackets, include: Attanasio and Brugiavini (2003): -0.49 (ages 45-54), -0.21 (ages 56-60), -0.11 (ages 61-65) [Instrumental Variables (IV), Italy]; Attanasio and Rohwedder (2003): -0.75 [Ordinary Least Squares (OLS), UK, ages 55-64]; Engelhardt and Kumar (2011): -0.50 [median regression]; Gale (1998): -0.77 [median regression]; Gustman and Steinmeier (1999): .012 [median regression]; Hubbard (1986): -0.16 (pensions), -0.33 (SS) [OLS]; Hurd, Michaud, and Rohwedder (2009): 0.44 [OLS, aggregate cross-country data]; Kapteyn et al. (2005): -0.11 [median regression].
} 
surprising that SS crowdout is quite a bit larger than DB crowdout (-0.33 vs. -0.13$)$. Few studies have estimated crowdout separately for pensions and Social Security. One well known study that did reported results that are virtually identical to the simulation results reported here: -0.16 for DB and -0.33 for SS (Hubbard, 1986). DC account balances are fairly liquid, so it is quite surprising to find that DC crowdout is only $-0.09 .{ }^{20}$

The initial assets of $41 \mathrm{~K}$ and initial DC balance of $17 \mathrm{~K}$ are based on HRS data for single men, so they are not arbitrary. But the model is nonlinear, and it is interesting to examine whether crowdout behavior is sensitive to initial conditions. In the presence of a liquidity constraint, crowdout must be zero if a household has zero wealth. As the initial wealth endowment increases, one would expect crowdout to increase, at least up to a point. The lower panel of Table 3 reports simulated crowdout results using initial assets of 150 and an initial DC balance of 60 . This yields proportional crowdout of $-0.18,+0.06$, and -0.76 , for DB, DC, and SS, respectively. Crowdout is much larger when initial wealth is higher in the case of SS, a bit larger for DB, and smaller (actually, positive) for DC. The results are again rather surprising, as they show the expected pattern only for SS.

These results raise an important question: which features of the model account for such low crowdout for DB and DC pensions, and less than one-for-one crowdout more generally? The three key features that distinguish the model from the simpler version implicit in the empirical

${ }^{20}$ Claiming the DC balance before age 60 results in a tax penalty of $10 \%$ of the balance The DC balance is claimed before age 60 in only $7 \%$ of the simulated cases (see Figure 4). The tax advantages of a DC plan should encourage households to use privately held assets to smooth consumption, and resort to the DC balance only after private assets are exhausted. The model assumes an all-or-nothing claiming decision, but in reality households can borrow against the DC balance and/or claim it in installments. Accounting for these possibilities might increase the liquidity of DC balances. 
literature are the liquidity constraint, uncertainty, and choice of retirement and claiming ages. I examine each of these below, alone and in combination.

One might expect larger crowdout if there was no liquidity constraint. Intuition from the simple life cycle model suggests that the ability to borrow against future pension benefits would reduce the need to save in order to finance consumption until the benefit can be claimed. On the other hand, in the presence of uncertainty a liquidity constraint may not be binding, since risk aversion will induce individuals to save for precautionary reasons. To study this issue, I solved a version of the model with no liquidity constraint. Two issues complicate the interpretation, however. Allowing individuals to take on an arbitrarily large amount of debt typically results in a consumption splurge in the first period. In order to avoid this sharp and unrealistic discontinuity, I impose a lower bound on wealth of $-50 \mathrm{~K}$ at age 51 , rising to zero at age $100 .^{21}$ The second issue is the consumption floor, which is equal to $5 \mathrm{~K}$ in the simulations. The existence of a consumption safety net dampens the impact of relaxing the liquidity constraint, since going into debt will never cause starvation. Thus, relaxing the liquidity constraint has very little impact with the consumption floor in place. Therefore, when the liquidity constraint is relaxed, the consumption floor is set to a much lower value: $\overline{\mathrm{C}}=0.5 \mathrm{~K}$.

Table 4 shows results from crowdout simulations for a variety of model specifications. The first column repeats the results from Table 3 for the baseline specification. The second column shows the results from a specification with no liquidity constraint. Relaxing the liquidity constraint reduces DB and DC crowdout a bit, but increases SS crowdout from -0.33 to -0.55 . In

${ }^{21}$ This is similar to the approach used by Van der Klaauw and Wolpin (2008). They estimated the lower bound in the initial period rather than imposing it arbitrarily as I do here. 
the absence of a liquidity constraint SS claiming is delayed from age 63 to 66 . The delay in claiming suggests that relaxing the liquidity constraint enables individuals without pensions to avoid early claiming and thereby take advantage of the relatively high rate of return to delayed claiming. ${ }^{22}$ The same logic applies to pensions, and claiming ages are in fact delayed by 1-2 years when the liquidity constraint is relaxed. It is unclear why this does not result in larger crowdout.

Uncertainty generates a precautionary saving motive, which could affect crowdout. Column 3 of Table 4 shows results for a model specification with no uncertainty. The length of life is known in advance, with death occurring at age 85. Eliminating uncertainty has little impact on DB and SS crowdout (compare columns 1 and 3), but has a large impact on DC crowdout, increasing it from -0.09 to -0.58 . Without uncertainty there is no precautionary saving. In this case the DC balance apparently is a good substitute for saving for retirement, the only remaining motive for saving in the model.

The third main feature that differentiates the model used here from the simple life cycle model is that individuals make employment and pension claiming choices. To examine the importance of these choices, I respecified the model assuming a fixed age of exit from the labor force and assuming that Social Security benefits must be claimed upon leaving employment. I also eliminate the options of changing employers and reentering employment. In this specification, the individual is forced to work through age 64, and claims the SS and DB benefits

${ }^{22}$ The OASI Delayed Retirement Credit for the 1937 birth cohort is .065. This is the amount by which the benefit increases per year of delay in claiming past the full retirement age. 
at age $65 .{ }^{23}$ Column 4 reports results for this specification. Eliminating the employment choice results in substantially greater crowdout in all three cases. Crowdout is -0.41 for $\mathrm{DB},-0.38$ for DC, and -0.64 for SS (compare to column 1). When employment is a choice, an increase in pension wealth increases the demand for both leisure and consumption. As shown in Figure 1, pensions and, especially, Social Security increase demand for leisure by a large amount. When this option is eliminated, the only one way to use additional pension wealth is to increase consumption, causing a decline in saving. This is evidently a key reason why crowdout may be small in practice: there is a significant wealth effect on the demand for lifetime leisure. ${ }^{24}$

Column 5 reports results from a specification with no employment choice, no uncertainty, and no liquidity constraint. Employment choice is evidently the only model feature that matters much for DB crowdout. Uncertainty alone can account for the entire difference in the DC crowdout effect between columns 1 and 5 . This indicates that the effects of uncertainty and employment choice are not additive. In the case of SS crowdout, the liquidity constraint and employment effects reinforce each other, with the combined effect larger than either of the individual effects.

The model specification reported in column 5 is close to the stylized model described at the end of Section 2. Yet crowdout is less than 1 in absolute value in all three cases: -0.46 for DB, -0.59 for DC, and -0.80 for SS. One additional feature that distinguishes the model from the stylized version is the income tax. This could be important because of the tax advantages of

\footnotetext{
${ }^{23}$ The DC claiming decision is still included in this specification, but the results are very similar if DC claiming is also mandatory following exit from employment.

${ }^{24}$ There are also substitution effects, but these are more difficult to characterize, since they encourage employment at some ages and leisure at other ages.
} 
pensions and Social Security. Eliminating the income tax, and therefore the tax benefit of saving in a DC plan, might be expected to increase substitutability between DC saving and household wealth. Social Security benefits are taxed differently from other income, so SS crowdout may be affected as well..$^{25}$ To determine whether this is the case, I solved and simulated a specification like the one in column 5, but eliminating taxes. As illustrated in column 6 , this hardly affects DB crowdout, but does result in a large increase in DC crowdout, from -0.59 to -0.87 , and SS crowdout increases modestly as well, from -0.80 to $-.88 .{ }^{26}$

To summarize, crowdout of -0.87 and -0.88 for DC and SS in column 6 is close enough to -1.0 to indicate that model specification can largely account for the difference in crowdout between the most general and most restrictive versions of the model. However, this is clearly not the case for DB crowdout, which never exceeds -0.46 in any specification. I explored two possible explanations for this. First, as noted above, DB pension formulas can be quite complex, and the approximation I developed (described in Appendix B) could be inaccurate. In order to determine if this is the case, I created a fictitious DB pension plan with a very simple benefit formula that requires no approximation. ${ }^{27}$ Solving the model with this pension plan produced

\footnotetext{
${ }^{25} \mathrm{~A}$ portion of the Social Security benefit is excluded from taxable income, with a higher proportion excluded for low income households. The portions excluded are $100 \%$ for low income households, $50 \%$ for medium income households, and $15 \%$ for higher income households. In the no-income-tax scenario the SS payroll tax remains part of the model.

${ }^{26}$ Other features of the model that could be important for crowdout are institutional restriction on the ages at which pensions and SS can be claimed. However, in the absence of a liquidity constraint, it seems that these should not matter. Simulations from a specification that eliminated age restrictions on claiming produced results very similar to those in column 6 , with a small increase in SS crowdout from -0.88 to -0.93 the only notable effect.

${ }^{27}$ Let $y$ be years of enrollment in the plan at the time of exit from the pension-providing firm. The annual benefit in the fictitious plan is determined as $b=0$ if $y<26, b=0.025 \cdot y \cdot A I M E$ if $26 \leq y<33$, and $b=.035 \cdot y \cdot A I M E$ if $y \geq 33$. I solved the model analytically in this case as well,
} 
results very similar to those reported in Table 4 . The same was true when other actual DB pension plans from the HRS were used in solution in place of the plan used in the main analysis. This indicates that accuracy of the approximation to complex DB benefit formulas is not a problem. Second, I simulated a scenario with a DB plan and no SS. This exercise compares the no-pension-no-SS (NPNSS) scenario to a DB scenario with no SS. DB crowdout in this case is 0.62 , larger than -0.46 , but still relatively far from -1.0 . Thus it remains unclear why the model fails to generate one-for-one crowdout in the DB scenario under the simplest specification.

\section{Compensating Variation}

The value of a pension is measured here by the compensating variation (CV): the amount by which the initial assets of a household with a pension must be reduced in order to equate its EPDV of optimized lifetime utility (value function) at age 51 to that of the same household without a pension. Dividing the CV by initial pension wealth at age 51 provides a measure with the same scale as the proportional crowdout measure. Table 5 reports CV figures for the baseline specification from Table 3. For the baseline case with initial assets of 41, providing a household with the particular DB pension used in the model solution requires initial wealth to be reduced from 41 to -24 in order to equate lifetime utility to the NP case. The CV is $41-(-24)=65$. The EPDV of lifetime DB benefits at age 51 is 136 . Thus the value of the pension to the household is $65 / 136=0.48$, or $48 \%$ of pension wealth. This indicates that DB pensions are worth less than half their EPDV, given that the household is eligible for Social Security. However, in the hypothetical case in which a household is not eligible for SS, the CV for the DB pension is 1.50, indicating that a DB pension is very valuable if it is the only annuity.

and verified that crowdout is one-for-one. 
In the DC case the $\mathrm{CV}$ is 1.35 times the DC balance of 17 , indicating that DC pensions are valued by households at about one third more than their dollar value, even conditional on eligibility for SS. This is probably due to their tax-advantaged status, as well as their relatively high liquidity. For SS, the CV calculation equates the EPDV of lifetime utility of the NPNSS case to that of the NP case. This requires increasing initial wealth in the NPNSS case from 41 to 156, yielding a CV of $156-41=115$. This is 1.49 times SS wealth of 77 at age 51 . Social Security is evidently of considerable value to a household that would otherwise have to fully finance its consumption expenditure in retirement through saving. This may be due in part to the assumption that there is no market for annuities. As noted above, Social Security has a large impact on the demand for leisure, which could help explain why its value to households exceeds its EPDV. An alternative calculation of the CV for SS for the case in which the individual has a DB pension yields a CV of 0.99 for SS, again indicating that the second annuity is worth less when the individual already has one. However, SS is inherently more valuable than DB, likely due to inflation protection.

The results in the lower panel of Table 5 evaluate the value of pensions and SS for a wealthier household, with initial wealth of 150 and an initial DC balance of 60. DC pensions are evidently worth much less to a wealthier household, but DB and SS are more valuable. The latter result is somewhat counterintuitive.

\section{E. Regression Estimates of Crowdout}

Here I explore whether regression estimates of crowdout based on the assumptions of the stylized life cycle model are a reasonably accurate guide to behavior when the data are generated from a process that does not obey these strong assumptions. The simulation approach used to 
generate the data is somewhat different from the approach used above. The results in Tables 3-5 are based on simulations of four cases (NP, DB, DC, and NPNSS), but a sample size of four is too small for the regression analysis. Instead I simulate several different scenarios for each of the four pension/SS cases, varying initial assets, the initial DC balance, AIME, and the length of service in the pension job. This resulted in 145 simulated scenarios. In each scenario I choose the age at which to measure pension wealth and assets using the same criterion as in the crowdout analysis: the latest age at which no more than $25 \%$ of simulated cases have claimed the pension or Social Security.

Table 6 reports coefficient estimates on pension and Social Security wealth in household wealth regressions. I computed the life cycle adjustment factor ( $\kappa_{t}$; see page 14$)$ using a continuous time approximation from Gale (1998). The other regressors are those implied by the theory: the EPDV of remaining lifetime earnings, current period earnings, and household wealth in the previous period. This dynamic specification has the advantage of removing to some extent the influence of the initial conditions: the estimates represent the impact of an additional dollar of pension wealth on household wealth, holding constant wealth in the previous period. The estimates in column 1 using measures of pension wealth derived from the model indicate crowdout of -0.21 in the DB case, -0.31 for DC pensions, and -0.63 for SS. These estimates are larger than the "true" crowdout measures of $-0.13,-0.09$, and -0.33 reported in Table 3 , especially for the DC and SS cases. Using more standard measures of pension wealth based on the assumptions of the stylized version of the life cycle model yields very similar estimates. This suggests that the difference between the true crowdout measures and regression estimates is due to assumptions of linearity and that pension wealth is a sufficient statistic for the effects of 
pensions.

For comparison with the more common cross section regression models used in the literature, columns 3 and 4 present estimates from a specification that does not control for lagged wealth. This specification yields systematically larger crowdout estimates, suggesting that the cross sectional approach to analyzing crowdout may be seriously misleading.

\section{F. Sensitivity Analysis}

Table 7 shows crowdout results based on alternative parameter values and initial conditions. The baseline assumptions and results are shown in the first row. Simulated DB crowdout is relatively insensitive to all of the variations shown in the table, with crowdout of between -0.01 and -0.17 . The same is true in the DC case, with the exception of the anomalous finding of crowdout of +1.32 with a coefficient of relative risk aversion of $\alpha=0.5$. SS crowdout is more sensitive, with a tendency for greater crowdout when risk aversion is higher, though the pattern is not monotonic. A higher interest rate causes greater crowdout, while a higher rate of time preference reduces crowdout. This pattern is true for DB and DC as well.

\section{Policy Counterfactuals}

I briefly describe the results of simulations in which the Social Security Full Retirement Age (FRA) is increased from 65 to 66, 67, 68, and 69. The 1983 amendments to the Social Security Act increased the FRA in two month increments from 65 for birth cohorts up to 1937, to 66 for cohorts 1943-1954, and to 67 for cohorts born in 1960 and after. A one year increase in the FRA is equivalent to a $6.67 \%$ cut in the benefit, holding claiming age constant. ${ }^{28}$

\footnotetext{
${ }^{28}$ This is true for any claiming age between 63 and the FRA. The benefit cut is $5 \%$ if the benefit is claimed at 62. See Behaghel and Blau (2010) for additional discussion.
} 
The first column of Table 8 shows simulation results for the baseline case with FRA = 65, separately for the NP, DB, and DC scenarios. I examine three outcomes: peak assets, mean retirement age, and lifetime utility. The second column shows that increasing the FRA to 66 is predicted to increase peak assets by 2.6 to $4.0 \mathrm{~K}$ (3-4\%), increase the mean age of retirement by 0.5 to 0.9 years, and reduce welfare by $3.6-3.9 \%$. The effects on saving and retirement are largest for the NP and DC scenarios, but lifetime welfare falls by about the same amount in all three cases. Note that lifetime welfare falls by considerably less than the decline in the SS benefit. Banerjee (2010) used the increase in the FRA as a quasi-experiment to estimate the magnitude of crowdout. His estimates imply that the increase in the FRA from 65 to 66 caused saving to increase by $4.5 \mathrm{~K}$, which in his HRS sample was a $1.5 \%$ increase. In percentage terms, the simulations presented here predict a larger response. Mastrobuoni (2009) estimates that the increase in the FRA from 65 to 66 caused the mean age of retirement to increase by about 0.5 years.

The remaining columns of Table 8 show the simulated effects of further increases in the FRA. The scheduled increase to 67 is predicted to evoke a saving response of about the same magnitude as the increase to 66, while the retirement response is only about half as large. Further increases to 68 and 69 cause saving to increase by smaller amounts. Raising the FRA to 69, which is equivalent to a $13.3 \%$ benefit cut beyond the already scheduled increase to 67 , is predicted to increase mean retirement age by about another year, except for DB, and increase saving by another 1.4-4.9K. The cumulative welfare impact of the increasing the FRA from 65 to 69 is $8-9 \%$, while the implied benefit cut is $26.7 \%$. The option to substitute between leisure and consumption is clearly responsible for the difference between the magnitudes of the benefit and welfare losses. The generally smaller effects in the DB scenario reflects the fact that SS is one of two annuities available in this case. 


\section{Conclusions}

The impact of public and private pensions on household behavior and welfare is of considerable importance in a rapidly aging world. Empirical studies of crowdout in recent years have focused on identification issues, which are obviously important for obtaining useful estimates. I take a different, and complementary, approach, studying crowdout behavior in a model that incorporates choice alternatives and constraints more realistically than in the stylized life cycle model that is the basis for empirical analysis. The results show that modeling choices matter: regression estimates of crowdout are too large compared to simulated crowdout, and allowing for choices and constraints that are usually omitted from analysis affects the 'true' magnitude of crowdout. The results clearly are not definitive, but they illustrate the potential pitfalls of a simple regression approach to empirical modeling of a complex nonlinear process. Two other key advantages of the modeling approach used here are the ability to derive welfare implications of pensions, and to predict the effects of recent and proposed future SS and pension policy changes on saving and retirement.

The obvious next step in this line of research is to estimate the model structurally. I started this project intending to do so, but I did not fully appreciate the difficulties caused by pension heterogeneity. Each DB pension is different from others, and a global approach to approximating the value function as in van der Klaauw and Wolpin (2008) was unsuccessful in capturing this variation. As a result, I used a local approximation method, which unfortunately greatly limits modeling flexibility due to computer memory constraints and computation time. As computation power continues to become cheaper, structural estimation of the model with multiple pension plans should become feasible in the future. 


\section{Appendix A: Value Function Interpolation}

The value function in period $t$ can be written as

$$
\begin{aligned}
V_{t}\left(\boldsymbol{S}_{t}\right)= & \max \left\{u\left(c_{t}, j_{t}\right)+\delta \mathrm{E}_{t}\left(V_{t+1}\left(\mathbf{S}_{\mathbf{t}+1} \mid c_{t}, j_{t}, d_{t}, \boldsymbol{S}_{t}\right)\right\}\right. \\
c_{t}, j_{t}, d_{t} &
\end{aligned}
$$

where $\boldsymbol{S}_{\boldsymbol{t}}$ is the vector of state variables at the beginning of period $t, d_{t}$ is the DC pension and/or Social Security choice, if relevant, $c$ is consumption, and $j$ is the employment choice. The expectation of the $t+1$ value function can only be approximated. Let $S_{i t+1}$ be the value of the $i^{\text {th }}$ continuous state variable $(i=1,2,3)$ in period $t+1$. Define $k_{i}$ as the grid point for state variable $i$ for which $\mathrm{G}_{\mathrm{it}+1 \mathrm{k}_{\mathrm{i}}-1}<\mathrm{S}_{\mathrm{it}+1} \leq \mathrm{G}_{\mathrm{it}+1 \mathrm{k}_{\mathrm{i}}}$, where $G_{i t+1 \mathrm{k}}$ is the value of state variable $i$ at grid point $k$ in

period $t$. For given values of the discrete state variables, the continuation value is approximated by multidimensional linear interpolation (Judd, 1998):

$$
\mathrm{E}_{\mathrm{t}}\left(V_{t+1}\left(S_{1 t+1}, S_{2 t+1}, S_{3 t+1} \mid c_{t}, j_{t}, d_{t}, S_{t}\right)\right) \approx \sum_{\mathrm{b}_{1}=0}^{1} \sum_{\mathrm{b}_{2}=0}^{1} \sum_{\mathrm{b}_{3}=0}^{1} \kappa_{\mathrm{b}_{1} \mathrm{~b}_{2} \mathrm{~b}_{3}} \overline{\mathrm{V}}_{\mathrm{k}_{1}+\mathrm{b}_{1}, \mathrm{k}_{2}+\mathrm{b}_{2}, \mathrm{k}_{3}+\mathrm{b}_{3} \mathrm{t}+1},
$$

where the last term is the value function evaluated at grid points $k_{1}+b_{1}, k_{2}+b_{2}, k_{3}+b_{3}$. The weight inside the summation is an inverse function of the Euclidian distance between the point $\left(S_{1 t+1}, S_{2 t+1}, S_{3 t+1}\right)$ and the cube with vertices $\left(G_{1 k 1-1 t+1}, G_{1 k 1 t+1}\right),\left(G_{2 k 2-1 t+1}, G_{2 k 2 t+1}\right),\left(G_{3 k 3-1 t+1}, G_{3 k 3 t+1}\right)$ :

$$
\kappa_{b_{1} b_{2} b_{3}}=\frac{\kappa_{b_{1} b_{2} b_{3}}^{*}}{\sum_{c_{1}=0}^{1} \sum_{c_{2}=0}^{1} \sum_{c_{3}=0}^{1} \kappa_{c_{1} c_{2} c_{3}}^{*}} \text { and } \kappa_{b_{1} b_{2} b_{3}}^{*}=\sqrt{3}-\sqrt{\sum_{i=1}^{3}\left(\frac{S_{i t+1}-G_{i t+1 b_{i}-1}}{G_{i t+1 b_{i}}-G_{i t+1 b_{i}-1}}\right)^{2}}
$$

The $V_{t+1}$ term was computed and stored as part of the solution in period $t+1$. Given the 
inequalities that define $k_{i}$, the maximum possible value of each of the three terms under the square root sign is one, so the maximum possible value of the square root expression itself is $\sqrt{ } 3$. Subtracting it from $\sqrt{ } 3$ ensures that the weight cannot be negative. Scaling by the sum of the $\kappa^{*}$ terms ensures that each weight is between zero and one and that the weights sum to one. In some circumstances, only one or two dimensional interpolation is required.

The grids are chosen so that all possible values of the continuous state variables are interior to the grid, in order to avoid extrapolation. This is straightforward for AIME, which is stationary and has an upper bound determined by SS rules, but the maximum feasible values of assets and the DC balance increase over time. The asset and DC balance grids are set each period to ensure that any feasible value of assets and the DC balance, conditional on the period $t-1$ values, fall within the relevant grid.

The EPDV of the SS and DB benefits are interpolated using the same approach, for periods before the benefit has been claimed. This is necessary because the benefits depend on when they are claimed, which is uncertain and subject to choice. To illustrate in the case of SS, the latest age at which SS can be claimed is 70. At age 70, the SS benefit can be calculated as a function of AIME at each grid point for those points in the state space at which the SS benefit has not yet been claimed. The EPDV of the benefit for claiming at age 70 is easily calculated since it does not depend on future choices and realizations of random variables, except for the interest rate and mortality. These EPDV values are stored, and used in interpolating the EPDV of SS benefits at age 69 for state points in which the benefit has not been claimed by age 69 , and for choices in which it is not claimed at 69. The same approach is used for the EPDV of DB benefits, where the last age at which the benefit can be claimed is, by assumption, 65 . The grids used in solution contain 70 points for assets, 15 for AIME, and 15 for the DC balance. 


\section{Appendix B: Calculating Defined Benefit Pension Benefits}

HRS respondents who reported any pension coverage at wave 1 were asked for permission to contact the employer to obtain information on the pension plan. For respondents who gave permission and whose employers provided the requested information, the formulas that determine the pension benefit for each plan were coded by the HRS staff and provided to researchers on a restricted access basis, along with pension calculation software. These formulas determine the pension benefit for all possible scenarios involving birth date, age, years in the plan at the time of exit, and salary history. Rather than use the pension calculation software (which is coded in Visual Basic) to directly compute benefits for each individual, I used an approximation approach. This was done so that the benefit calculations could be easily computed in the Fortran program used to solve and simulate the model.

The approximation approach uses the pension calculation software to compute benefits for each DB plan in which any respondent is enrolled at wave 1, for 5,000 artificial individuals, with alternative combinations of birth date, hire date, real salary level, and salary growth rate. For each artificial individual and each plan, I computed the monthly pension benefit and the age at which the individual is first eligible for the benefit for every possible age at which the individual could quit from the year after the hire date through age 75 .

I then ran three regressions, separately for each pension plan, using the 5,000 observations for each plan. The dependent variables are (1) a binary indicator for whether the individual will ever be eligible for a benefit, given the age at exit; (2) the age at which the individual is first eligible for the benefit, conditional on ever being eligible; and (3) the monthly benefit, conditional on eligibility. Each regression is specified with a very flexible functional 
form, with dummies for age at exit, tenure at exit, and combinations of age and tenure at exit. For the benefit regression, the specification includes average salary in the most recent five years, the second most recent five years, and so forth, and interactions of the salary averages with age and tenure dummies.

The coefficient estimates from these regressions for each plan are stored, and used to predict benefits in the solution and simulation of the model. These regressions are generally very accurate in predicting outcomes. I compared the predictions from the regressions to the values computed directly from the pension calculator. For the "ever eligible" regression, using the rule that the prediction is zero if the fitted value is less than 0.5 and the prediction is one otherwise, the regression predicts every one of the approximately 5,000 observations correctly for $78 \%$ of the plans, and never predicts more than 13\% incorrectly for any plan. Two thirds of the first-ageof-eligibility regressions predict the correct age exactly for every observation, and the $5^{\text {th }}$ and $95^{\text {th }}$ percentiles of the rounded residual distribution are 1 and -1 respectively. Finally, for the annual benefit regressions, the mean prediction error is -2.7 (in thousands of dollars per year), the median error is -0.6 , the $75^{\text {th }}$ percentile of the prediction error is 0.6 , and the $25^{\text {th }}$ percentile is -8.5. Comparing the benefits predicted from this approach with the actual benefit reported by HRS respondents who retired during the panel, given actual quit dates, yields a mean prediction error of 3.0 and a median of 2.7. 


\section{References}

Attanasio, Orazio P., and Agar Brugiavini. 2003. "Social Security and household saving," Quarterly Journal of Economics 188 (3): 1075-1120.

Attanasio, Orazio P., and Susann Rohwedder. 2003. "Pension wealth and household saving: evidence from pension reforms in the United Kingdom,” American Economic Review 93 (5): 1499-1521.

Banerjee, Sudipto. 2010. “Does Social Security affect household saving?” Working paper, Ohio State University, October.

Behaghel, Luc, and David M. Blau. 2010. “Framing Social Security Reform: Behavioral Responses to Changes in the Full Retirement Age,” IZA Working Paper 5310, November.

Chan, Sewin, and Ann Huff Stevens. 2008. “What you don’t know can’t help you: pension knowledge and retirement decision-making," Review of Economics and Statistics, 90(2): 253-66.

Coile, Courtney, and Jonathan Gruber. 2007. "Future Social Security Entitlements and the Retirement Decision,” Review of Economics and Statistics 89 (2): 234-46.

Crawford, Vincent P., and David M. Lilien. 1981. "Social Security and the retirement decision," Quarterly Journal of Economics 96 (3): 505-29.

Engelhardt, Gary V., and Anil Kumar. 2011. "Pensions and household wealth accumulation," Journal of Human Resources, 46 (1): 203-36.

Engen, Eric M., William G. Gale, and Cori E. Uccello. 1999. “The Adequacy of Household Saving, Brookings Papers on Economics Activity, 2: 65-165.

Feldstein, Martin, 1974. "Social Security, Induced Retirement, and Aggregate Capital Accumulation,” Journal of Political Economy 82 (5): 905-926.

French, Eric. 2005. "The effects of health, wealth, and wages on labour supply and retirement behavior,” Review of Economic Studies 72 (April): 395-427.

Gale, William G. 1998. "The Effects of Pensions on Household Wealth: A Reevaluation of Theory and Evidence,” Journal of Political Economy 106 (4): 706-723.

Gourinchas, Pierre-Olivier, and Jonathan Parker. 2002. “Consumption over the life cycle,” Econometrica 70 (1): 47-90.

Gustman, Alan L., and Thomas L. Steinmeier. 1999. "Effects of pensions on savings: Analysis with data from the Health and Retirement Study," Carnegie-Rochester Series on Public Policy 50: 271-324. 
Gustman, Alan L., Thomas L. Steinmeier, and Nahid Tabatabai. 2010. Pensions in the Health and Retirement Study, Cambridge: Harvard University Press.

Hubbard, R. Glenn. 1986. "Pension Wealth and Individual Saving," Journal of Money, Credit, and Banking, 18 (2): 167-178.

Hubbard, R. Glenn, Jonathan Skinner, and Steven P. Zeldes. 1995. "Precautionary Saving and Social Insurance, Journal of Political Economy 103 (2): 360-399.

Hurd, Michael, Pierre-Carl Michaud, and Susann B. Rohwedder. 2009. "The Displacement Effect of Public Pensions on the Accumulation of Financial Assets,” Working Paper 2009-212, Michigan Retirement Research Center, September.

Judd, Kenneth L. 1998. Numerical Methods in Economics, Cambridge: MIT Press.

Kapteyn, Arie, Rob Alessie, and Anamaria Lusardi. 2005. "Explaining the wealth holdings of different cohorts: productivity growth and Social Security," European Economic Review 49: 1361-91.

Laibson, David I., Andrea Repetto, and Jeremy Tobacman. 1998. "Self-Control and Saving for Retirement,” Brookings Papers on Economics Activity, 1, 91-172.

Low, Hamish, Costas Meghir, and Luigi Pistaferri. 2010. "Wage risk and employment risk over the life cycle,” American Economic Review, 100(4): 1432-67.

Mastrobuoni, Giovanni. 2009. "Labor Supply Effects of the Recent Social Security Benefit Cuts: Empirical Estimates Using Cohort Discontinuities,” Journal of Public Economics 93 (11-12): 1224-33.

Purcell, Patrick, and Jennifer Staman. 2008. "Summary of the Employee Retirement Income Security Act (ERISA),” Congressional Research Service Report RL34443, April.

Scholz, John Karl, Ananth Seshadri, and Surachai Khitatrakun. 2006. “Are Americans Saving Optimally for Retirement?” Journal of Political Economy 114 (4): 607-643.

Social Security Administration. 2010. “Annual statistical Supplement to the Social Security Bulletin, 2009,” SSA Publication 13-11700, February.

Song, Jae, and Joyce Manchester. 2008. "Have People Delayed Claiming Social Security Benefits? Responses to Changes in Social Security Rules,” Social Security Bulletin 67 (2): 1-23.

Van der Klaauw, Wilbert, and Kenneth I. Wolpin. 2008. "Social Security and the Retirement and saving behavior of low income households,” Journal of Econometrics, 45 (1-2): 21-42. 
Table 1: Key Parameters in Calibration

\begin{tabular}{|c|c|}
\hline Parameter & Value \\
\hline \multicolumn{2}{|l|}{ Derived from estimates using Health and Retirement Study } \\
\hline Mortality hazard $\left(\pi_{t}\right)$ at ages $51,61,71,81,91,100$ & $\begin{array}{l}0.007,0.014,0.029 \\
0.057,0.111,0.190\end{array}$ \\
\hline $\begin{array}{l}\text { Mean out of pocket medical expenditure }\left(m_{t}\right) \\
\text { at ages } 51,61,71,81,91,100\end{array}$ & $\begin{array}{l}0.2,0.4,0.8,1.5,2.9 \\
5.6\end{array}$ \\
\hline Mean earnings $\left(w_{t}\right)$ at ages $51,61,71$ & $29.1,28.3,27.5$ \\
\hline Layoff probability $\left(\lambda_{\mathrm{t}}\right)$ at ages $51,61,71$ & $0.003,0.010,0.014$ \\
\hline \multicolumn{2}{|l|}{ Fixed arbitrarily } \\
\hline Coefficient of relative risk aversion $(\alpha)$ & 2.5 \\
\hline Consumption floor $(\overline{\mathrm{C}})$ & 5 \\
\hline Mean real rate of return $(\overline{\mathrm{r}})$ & .03 \\
\hline Rate of time preference $(\delta)$ & .03 \\
\hline Variance of log out-of-pocket medical expenditure shock & 1.0 \\
\hline Variance of log rate of return shock & 0.00020 \\
\hline Variance of log wage shock & .035 \\
\hline Annual inflation rate & .02 \\
\hline \multicolumn{2}{|l|}{ Calibrated to match employment patterns } \\
\hline Disutility of employment $\left(\gamma_{1}\right)$ & -.024 \\
\hline Additional disutility of employment if previously not employed $\left(\gamma_{2}\right)$ & -.18 \\
\hline $\begin{array}{l}\text { Additional disutility of employment if previously in a different job } \\
\left(\gamma_{3}\right)\end{array}$ & -.009 \\
\hline Variance of disutility of employment shock $\left(\sigma_{\varepsilon \ell}^{2}\right)$ & 0.0004 \\
\hline Variance of log utility of consumption shock $\left(\sigma_{\varepsilon c}^{2}\right)$ & 0.03 \\
\hline
\end{tabular}


Table 2: Initial Conditions for Simulations

\begin{tabular}{|l|l|l|}
\hline Variable & Value & Sample size \\
\hline Age & 51 & \\
\hline Education & 12 & \\
\hline White & 0 & \\
\hline Bad health & 0 & \\
\hline Birth year & 1937 & \\
\hline Age enrolled in pension plan & 30 & \\
\hline Job Tenure & 20 & \\
\hline Work experience & 30 & \\
\hline Assets (median) & 41 & 174 \\
\hline DC Balance (median) & 17 & 40 \\
\hline Average Indexed Monthly Earnings (AIME) & 30 & 135 \\
\hline
\end{tabular}

Notes: Monetary amounts are in thousands of 1992 dollars. The figures in the last three rows were computed from the Health and Retirement Study subsample of single white men aged 5153 who were employed in 1992 with annual earnings of at least 10K. Mean job tenure for this sample is 14 years, but I use 20 years as the initial condition in order to make the value of job tenure at age 51 consistent with the assumed pension enrollment age of 30 . 
Table 3: Pension Crowdout Computed Directly From Simulations

\begin{tabular}{|l|l|l|l|}
\hline & Defined Benefit & $\begin{array}{l}\text { Defined } \\
\text { Contribution }\end{array}$ & $\begin{array}{l}\text { Social } \\
\text { Security }\end{array}$ \\
\hline \multicolumn{4}{|c|}{ Initial Assets: 41, Initial DC Balance: 17 } \\
\hline $\begin{array}{l}\text { Age at which crowdout is } \\
\text { measured }\end{array}$ & 58 & 61 & 63 \\
\hline Dollar magnitude of crowdout & -23 & -5 & -42 \\
\hline Pension/SS wealth & 178 & 56 & 127 \\
\hline Proportional crowdout & -0.13 & -0.09 & -0.33 \\
\hline & Initial Assets: 150, Initial DC Balance: 60 & \\
\hline $\begin{array}{l}\text { Age at which crowdout is } \\
\text { measured }\end{array}$ & 57 & 52 & 62 \\
\hline Dollar magnitude of crowdout & -30 & +4 & -87 \\
\hline Pension/SS wealth & 170 & 69 & 115 \\
\hline Proportional crowdout & -0.18 & +0.06 & -0.76 \\
\hline
\end{tabular}

Notes: proportional crowdout $=$ dollar crowdout divided by pension/SS wealth. Monetary amounts are in thousands of 1992 dollars. Age at which crowdout is measured is the last age at which at least $75 \%$ of simulated individuals remain on the pension job or have not yet claimed Social Security. 
Table 4: Pension Crowdout Simulation Results Under Alternative Model Specifications

\begin{tabular}{|l|l|l|l|l|l|l|}
\hline Model Feature & \multicolumn{1}{|c|}{1} & \multicolumn{1}{|c|}{2} & \multicolumn{1}{|c|}{3} & \multicolumn{1}{|c|}{4} & \multicolumn{1}{|c|}{5} & \multicolumn{1}{|c|}{6} \\
\hline Employment choice & yes & yes & yes & yes & no & no \\
\hline Uncertainty & yes & yes & no & no & no & no \\
\hline Liquidity constraint & yes & no & yes & no & no & no \\
\hline Income tax & yes & yes & yes & yes & yes & no \\
\hline Defined Benefit & & & & & & \\
\hline Age & 58 & 59 & 58 & 58 & 64 & 64 \\
\hline Proportional crowdout & -0.13 & -0.07 & -0.10 & -0.10 & -0.46 & -0.45 \\
\hline Defined Contribution & & & & & & \\
\hline Age & 61 & 63 & 61 & 62 & 67 & 67 \\
\hline Proportional crowd out & -0.09 & -0.05 & -0.58 & -0.41 & -0.59 & -0.87 \\
\hline Social Security & & & & & & \\
\hline Age & 63 & 66 & 62 & 62 & 64 & 64 \\
\hline Proportional crowd out & -0.33 & -0.55 & -0.30 & -0.29 & -0.80 & -0.88 \\
\hline
\end{tabular}

Notes: In the scenarios with no employment choice, the mandatory age of retirement is 65 , so the last age at which at least $75 \%$ of individuals remain on the pension job is 64 . DC pension holders cannot claim until they leave the pension job, but they are not required to claim until age 70. It is assumed individuals claim Social Security benefits at age 65. In the no-employment scenarios, there is also no job switching or reentry. 
Table 5: Compensating Variation Associated with Pensions

\begin{tabular}{|c|c|c|c|c|}
\hline & $\begin{array}{l}\text { Initial } \\
\text { Assets }\end{array}$ & $\begin{array}{l}\text { Initial pension/SS } \\
\text { wealth }\end{array}$ & $\begin{array}{l}\text { Compensating } \\
\text { Variation (CV) }\end{array}$ & $\begin{array}{l}\mathrm{CV} /(\text { initial } \\
\text { pension/SS wealth) }\end{array}$ \\
\hline \multicolumn{5}{|c|}{ Initial Assets 41} \\
\hline DB & -24 & 136 & 65 & 0.48 \\
\hline DC & 18 & 17 & 23 & 1.35 \\
\hline NPNSS & 156 & 0 & & \\
\hline NP with SS & 41 & 77 & 115 & 1.49 \\
\hline \multicolumn{5}{|c|}{ Initial Assets 150} \\
\hline DB & 42 & 135 & 108 & 0.80 \\
\hline $\mathrm{DC}$ & 133 & 60 & 17 & 0.28 \\
\hline NPNSS & 259 & 0 & & \\
\hline NP with SS & 150 & 109 & 67 & 1.63 \\
\hline
\end{tabular}

Notes: The initial assets column shows the amount of initial wealth that equates the EPDV of lifetime utility in the DB and NP cases, the DC and NP cases, and the NP and NPNSS cases, respectively, given initial assets of 41 (upper panel) and 150 (lower panel) in the NP case. Initial pension/SS wealth shows the EPDV of future benefits (or the DC balance) at age 51. CV is initial assets in the DB or DC case minus initial assets in the NP case, or initial NP assets minus initial NPNSS assets. Monetary amounts are in thousands of 1992 dollars. 
Table 6: Regression Models of Wealth Using Simulated Data

\begin{tabular}{|l|c|c|c|c|}
\hline & \multicolumn{2}{|c|}{ Includes lagged wealth } & \multicolumn{2}{c|}{ Excludes lagged wealth } \\
\hline & \multicolumn{2}{|l|}{ Pension/SS wealth measure: } & \multicolumn{1}{l|}{ Pension/SS wealth measure: } \\
\hline & Correct & Perfect foresight & Correct & Perfect foresight \\
\hline EPDV DB benefit & -0.21 & -0.22 & -0.67 & -0.72 \\
\hline DC Balance & -0.31 & -0.35 & -0.89 & -1.01 \\
\hline EPDV SS benefit & -0.63 & -0.61 & -1.36 & -1.40 \\
\hline $\mathrm{R}^{2}$ & 0.98 & 0.97 & 0.79 & 0.77 \\
\hline
\end{tabular}

Notes: "Correct" refers to pension/SS wealth measures calculated as part of the model solution. "Perfect foresight" refers to pension/SS wealth measures calculated using the actual claiming ages, and assuming no uncertainty, no employment choice, and no liquidity constraint. The entries are coefficient estimates on the indicated variables in regression models of household wealth. EPDV = Expected Present Discounted Value, DB = Defined Benefit, DC = Defined Contribution, SS = Social Security. The other explanatory variables, with coefficient estimates from the specification in the first column, are: current annual earnings (-4.34), EPDV of remaining lifetime earnings (.002), and (in the first two columns) lagged wealth (2.11). Initial assets are 41. Sample size is 145 . Each observation is the mean over 300 random draws from a separate simulation, using the four pension/SS cases (NP, DB, DC, and NPNSS) in combination with alternative values of initial assets, the initial DC balance, the salary history, AIME, and the length of service in the pension job. One observation from each simulation is used: the one corresponding to the latest age at which no more than $25 \%$ of simulated cases have claimed the pension or Social Security. 
Table 7: Simulated Pension Crowdout Under Alternative Parameter Values and Initial Conditions

\begin{tabular}{|c|c|c|c|}
\hline & DB & DC & SS \\
\hline $\begin{array}{l}\text { Baseline: } \alpha=2.5, \overline{\mathrm{r}}=0.03, \delta=0.03, \mathrm{wc}=0.06 \text {, } \\
\text { ec }=0.03 \text {, age enrolled in } \mathrm{DB} \text { pension }=30\end{array}$ & -0.13 & -0.09 & -0.33 \\
\hline \multicolumn{4}{|l|}{ Coefficient of relative risk aversion $(\alpha)$} \\
\hline 0.5 & -0.01 & 1.32 & -0.31 \\
\hline 1.0 & -0.17 & -0.15 & +0.18 \\
\hline 1.75 & -0.06 & +0.10 & +0.01 \\
\hline 3.25 & -0.08 & -0.02 & -0.37 \\
\hline 4.00 & -0.02 & +0.01 & -0.87 \\
\hline 5.00 & -0.02 & 0.03 & -0.62 \\
\hline \multicolumn{4}{|l|}{ interest rate $(\overline{\mathrm{r}})$, rate of time preference $(\delta)$} \\
\hline$\overline{\mathrm{r}}=0.06, \delta=0.03$ & -0.14 & -0.30 & -0.70 \\
\hline$\overline{\mathrm{r}}=0.03, \delta=0.06$ & -0.09 & -0.07 & -0.13 \\
\hline \multicolumn{4}{|l|}{ Alternative DB plans } \\
\hline 1 & -0.12 & & \\
\hline 2 & -0.16 & & \\
\hline 3 & -0.09 & & \\
\hline \multicolumn{4}{|l|}{ Worker and employer DC contribution rates } \\
\hline $\mathrm{wc}=0.0$, ec $=0.06$ & & -0.20 & \\
\hline $\mathrm{wc}=0.06, \mathrm{ec}=0.12$ & & -0.17 & \\
\hline \multicolumn{4}{|l|}{ Age enrolled in DB plan } \\
\hline 35 & -0.11 & & \\
\hline 25 & -0.10 & & \\
\hline
\end{tabular}

Notes: $\mathrm{wc}=$ worker contribution to the DC pension. $\mathrm{ec}=$ employer contribution to the DC pension. The preference parameters $\left(\gamma\right.$ 's, $\sigma_{\varepsilon \ell}{ }^{2}$, and $\left.\sigma_{\varepsilon c}{ }^{2}\right)$ are recalibrated to generate reasonable employment patterns in each case. 
Table 8: Simulated Impact of Increasing the Social Security Full Retirement Age

\begin{tabular}{|l|l|l|l|l|l|}
\hline & Baseline FRA (65) & \multicolumn{5}{|c|}{ Effect of changing the FRA to : } \\
\hline & & 66 & 67 & 68 & 69 \\
\hline No Pension & & & & & \\
\hline Peak Assets & 88.6 & 3.5 & 7.7 & 11.9 & 12.6 \\
\hline Age of retirement & 63.1 & 0.9 & 1.4 & 1.9 & 2.4 \\
\hline Lifetime welfare & -.4237 & $-3.6 \%$ & $-5.1 \%$ & $-6.6 \%$ & -8.5 \\
\hline DB Pension & & & & & \\
\hline Peak Assets & 60.7 & 2.6 & 3.9 & 4.9 & 5.3 \\
\hline Age of retirement & 60.2 & 0.5 & 0.7 & 0.8 & 1.0 \\
\hline Lifetime welfare & -.3359 & $-3.9 \%$ & $-5.5 \%$ & $-7.2 \%$ & -9.1 \\
\hline DC Pension & & & & & \\
\hline Peak assets & 78.6 & 4.0 & 8.1 & 9.7 & 10.9 \\
\hline Age of retirement & 63.1 & 0.8 & 1.2 & 1.4 & 2.1 \\
\hline Lifetime welfare & -.3801 & $-3.6 \%$ & $-4.9 \%$ & -6.2 & -8.1 \\
\hline
\end{tabular}

Notes: In the baseline case, peak assets occur at ages 62, 59, and 63 for NP, DB, and DC, respectively. In the alternative scenarios the peak ages are one or two years later. Lifetime welfare is the value function in the first period. The simulation results shown here are based on a smaller grid size than the one used in the other results in the paper. Computer memory constraints made it impossible to simulate the impact of increasing the FRA beyond 66 without reducing the size of the state space. The grid sizes used here are 52 for assets and 10 for AIME, compared to 70 and 15 for the other results. Monetary amounts are in thousands of 1992 dollars. 
Figure 1: Simulated Employment Profiles

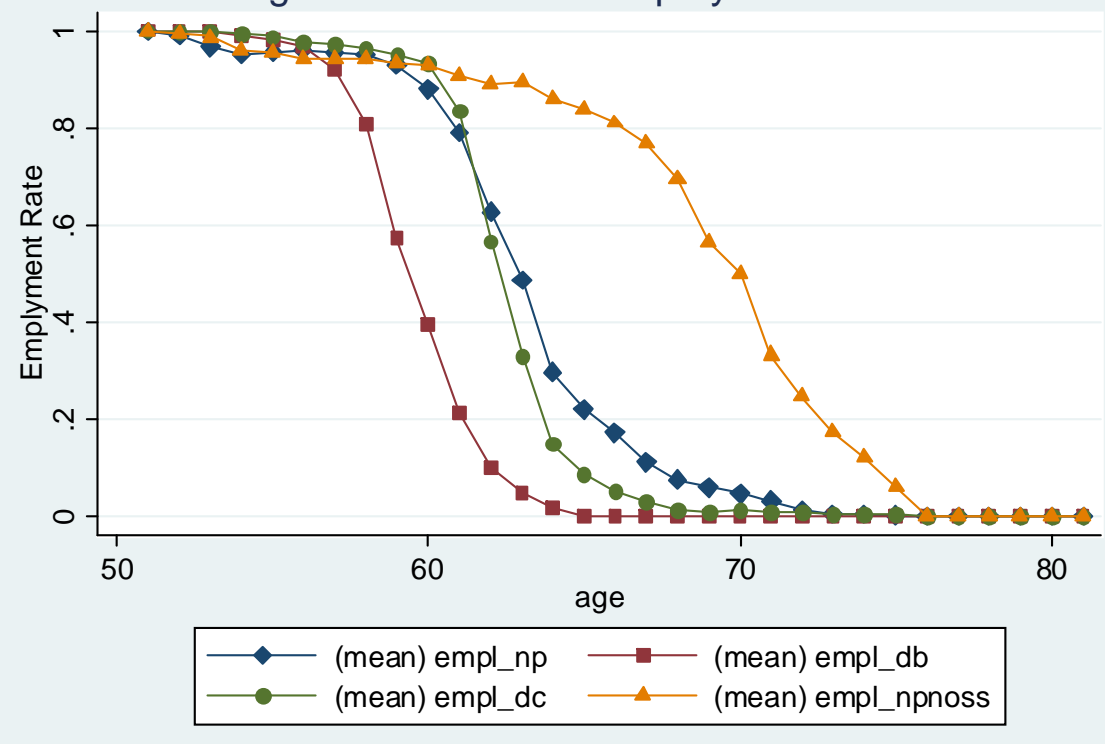

Figure 3: Mean Simulated Asset Profiles

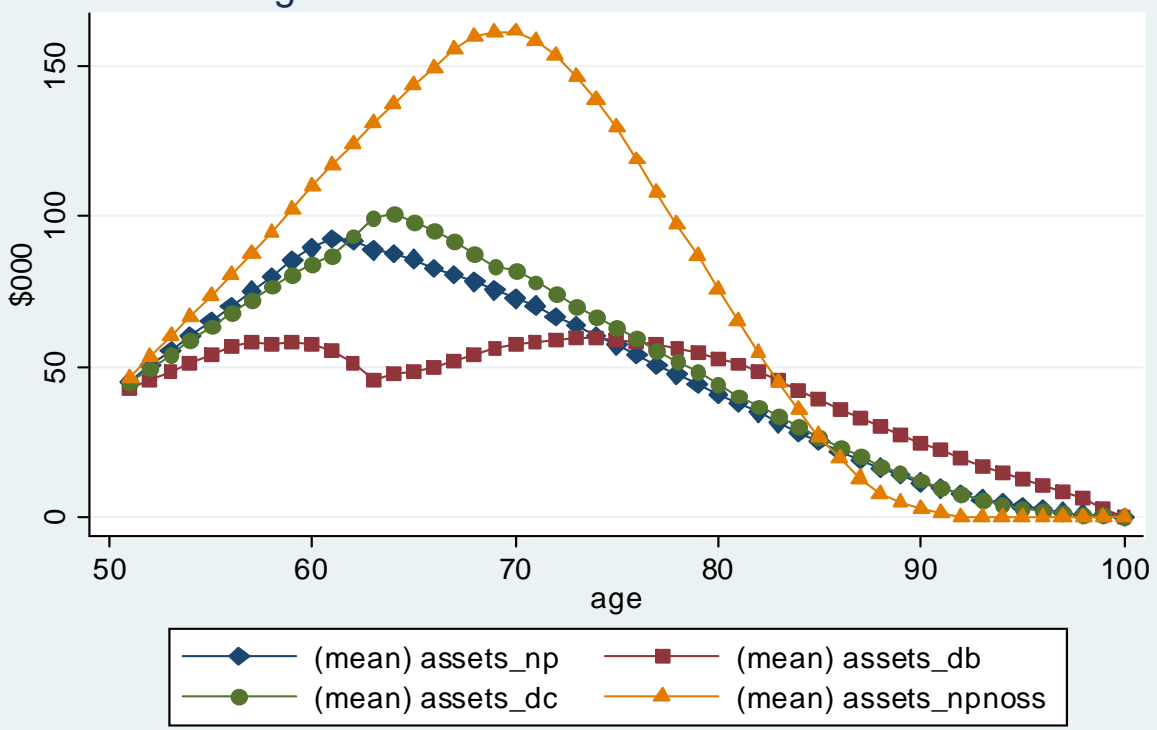

Figure 2: Mean Simulated Consumption Profiles

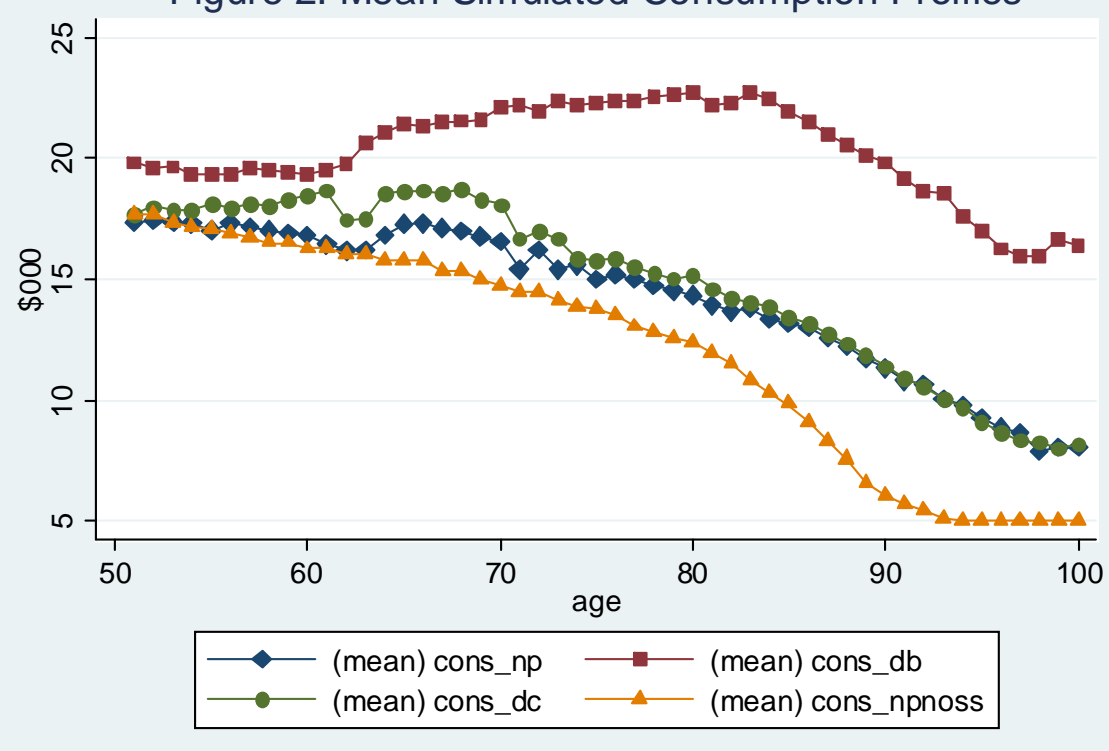

Figure 4: Simulated Pension Claiming Profiles

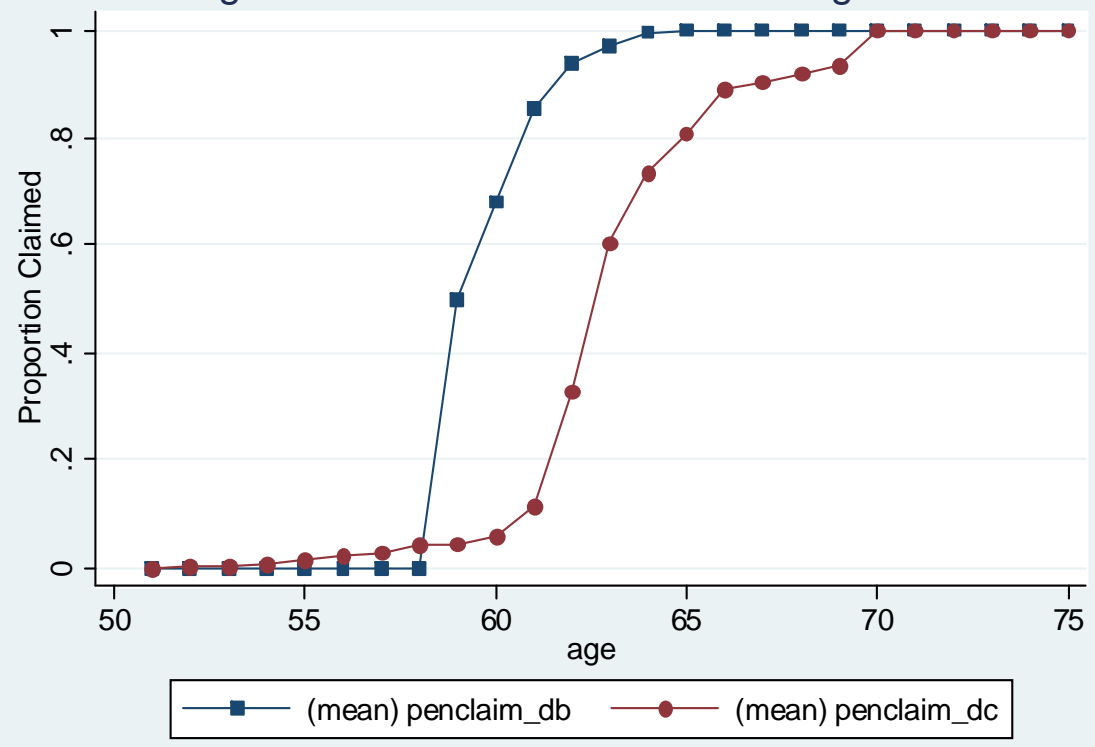


Figure 5: Simulated Social Security Claining Profiles

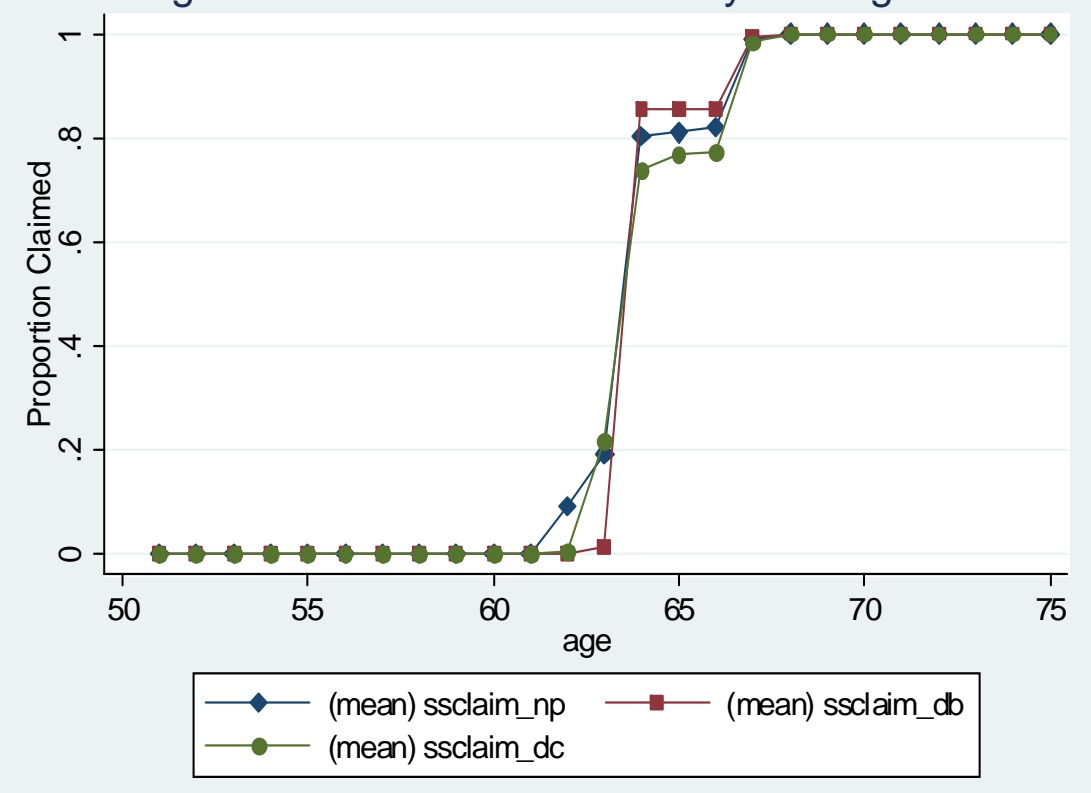

Figure 7: Defined Contribution Crowdout and DC Balance

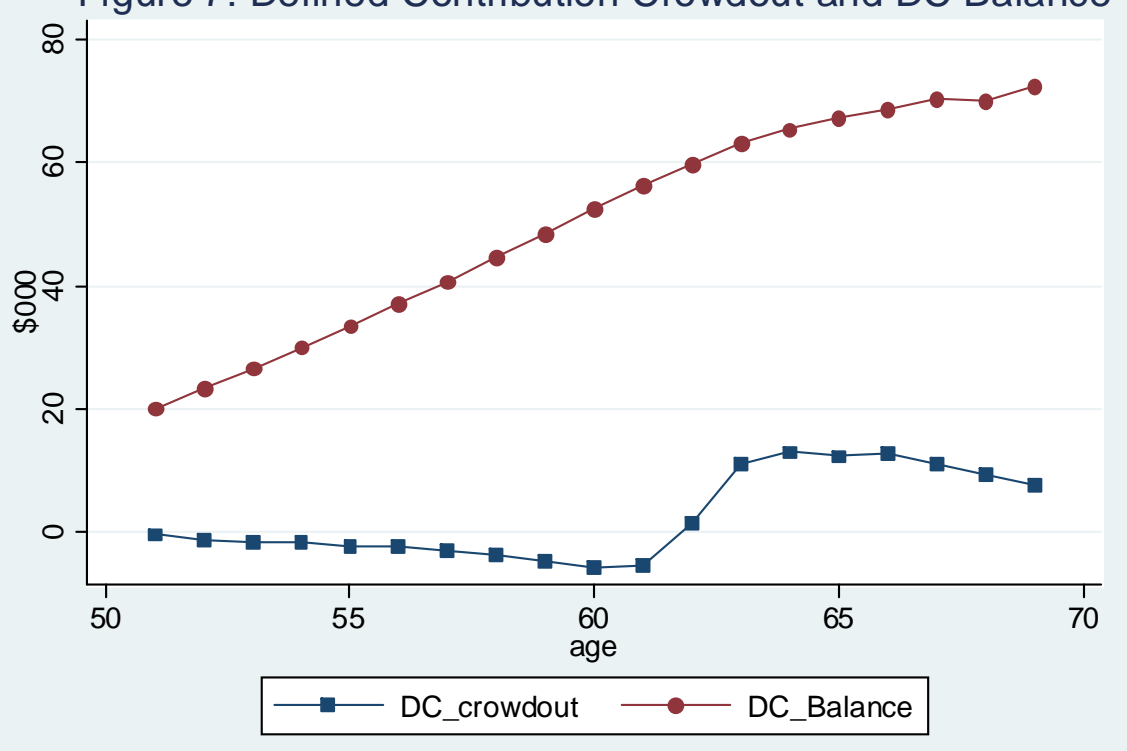

Figure 6: Defined Benefit Crowdout and EPDV of DB benefits

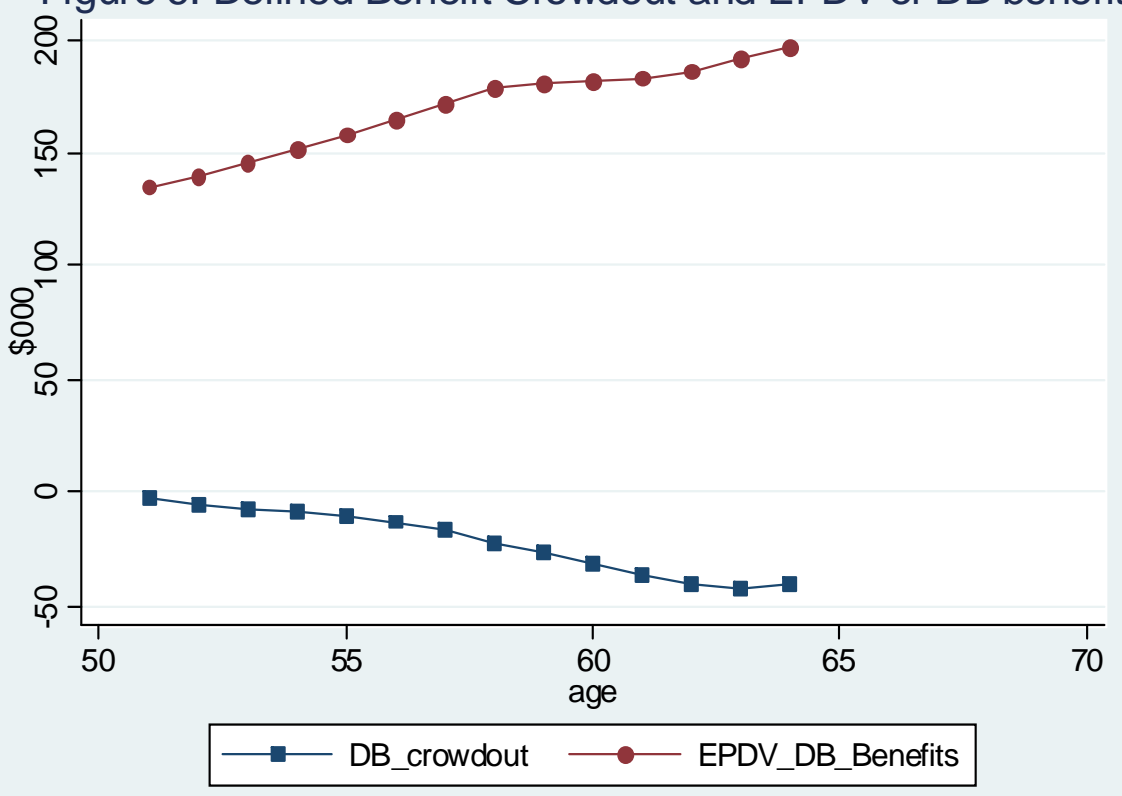

Figure 8: Social Security Crowdout and EPDV of SS benefits

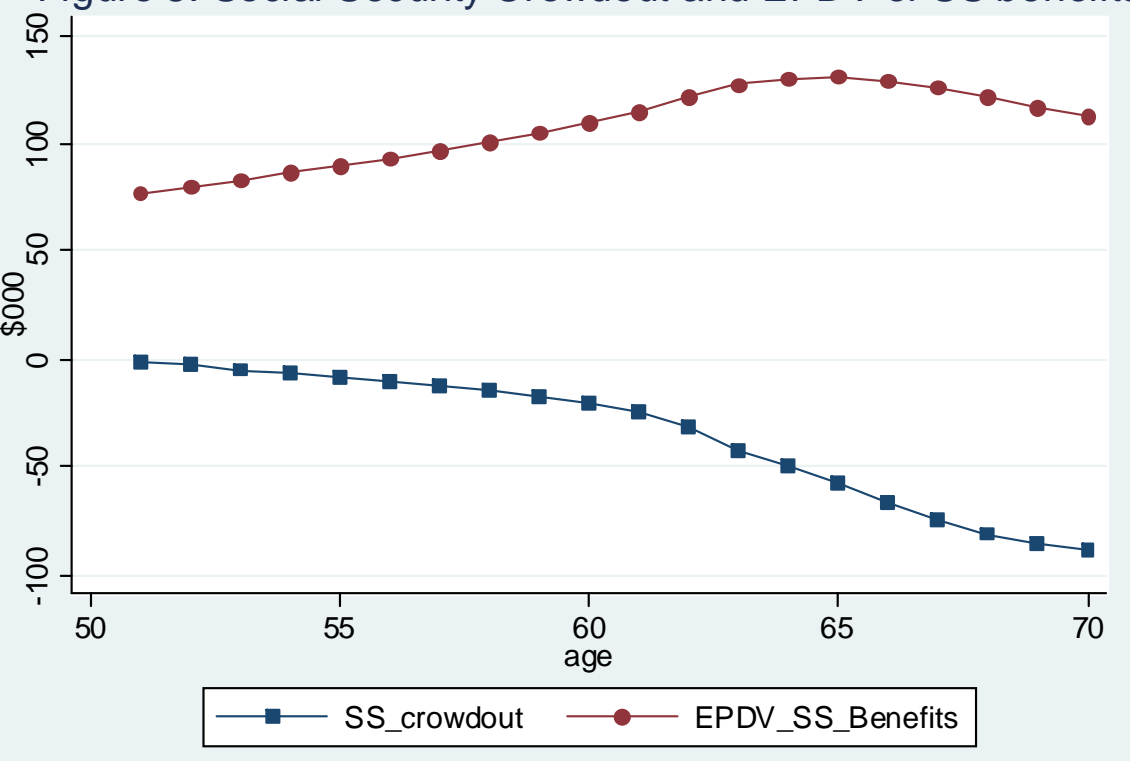




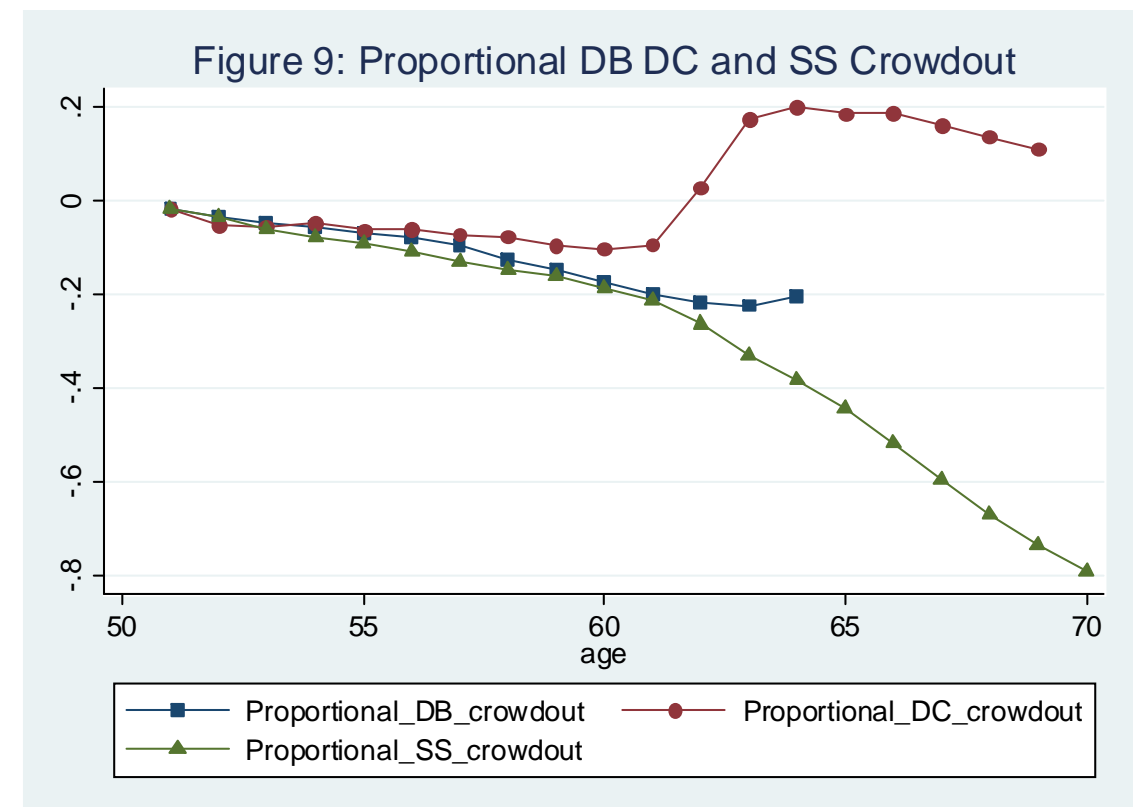


Appendix Table A1: Parameter Estimates from the Health and Retirement Study

\begin{tabular}{|l|l|l|l|}
\hline & Log wage & $\begin{array}{l}\text { Log medical } \\
\text { expenditure }\end{array}$ & Laid off (logit) \\
\hline Intercept & $3.03(.522)$ & $-8.237(.505)$ & $-8.371(1.497)$ \\
\hline Age & $-.0009(.016)$ & $.065(.005)$ & $.056(.016)$ \\
\hline Age squared & $-.0002(.013)$ & & \\
\hline Experience & $.0012(.0010)$ & & $-.011(.006)$ \\
\hline Experience squared & $-.00026(.00015)$ & & \\
\hline Job tenure & $.010(.001)$ & & $.040(.006)$ \\
\hline Job tenure squared & $-.0015(.0003)$ & & \\
\hline Bad health & $-.028(.013)$ & $.487(.042)$ & \\
\hline Education & $.022(.002)$ & $.099(.005)$ &.$- .037(.016)$ \\
\hline Lagged dependent & $.730(.008)$ & $.307(.007)$ & \\
\hline variable & & .030 .668 \\
\hline Black & $-.032(.015)$ & $-.328(.053)$ & $.08(.17)$ \\
\hline Birth year & $-.0005(.0018)$ & $.047(.006)$ & \\
\hline Part time & $-.021(.013)$ & & \\
\hline Mean squared error & .151 & & \\
\hline R squared & .646 & & \\
\hline Sample size & 7,526 & & \\
\hline
\end{tabular}

Notes: Fitted values from these regressions are used in solution and simulation. The explanatory variables that are not used as state variables in the model take on the following values in the predictions: experience $=30$, tenure $=20$, bad health $=0$, education $=12$, lagged dependent variable $=0$, black $=0$, birth year $=1937$, and part time $=0$. Standard errors are in parentheses. 
Appendix Table A2: Multinomial Logit Model of Two-Year Health Transitions

\begin{tabular}{|l|l|l|}
\hline Health in $t+2:$ & Bad & Dead \\
\hline Intercept & $-2.402(.722)$ & $-7.709(1.806)$ \\
\hline Age & $.030(.007)$ & $.078(.018)$ \\
\hline Education & $-.146(.007)$ & $-.077(.019)$ \\
\hline Birth year & $.008(.009)$ & $-.007(.022)$ \\
\hline Black & $.442(.070)$ & $.470(.177)$ \\
\hline Mean of dependent variable & .115 & .016 \\
\hline Sample size & \multicolumn{2}{|c|}{16,553} \\
\hline
\end{tabular}

Notes: The sample includes cases with self-reported good health in period $t$. The outcomes are good health in $t+2$, bad health in $t+2$, and dead in $t+2$. These coefficients are used to predict mortality risk, assuming good health in period $t$, education $=12$, birth year $=1937$, and black $=$ 0 . The probability of death is computed as $\exp \left\{M_{2}\right\} /\left(1+\exp \left\{M_{1}\right\}+\exp \left\{M_{2}\right\}\right)$, where $M_{1}$ is the fitted value from column 1 and $M_{2}$ is the fitted value from column 2 . The probability of remaining alive is $\left(1+\exp \left\{M_{2}\right\}\right) /\left(1+\exp \left\{M_{1}\right\}+\exp \left\{M_{2}\right\}\right)$. Standard errors are in parentheses. There is no straightforward way to convert two-year transition rates into one-year rates, so I use the two-year transition rates in solution and simulation. 
Figure A1: Simulated and Actual Employment Profiles: NP

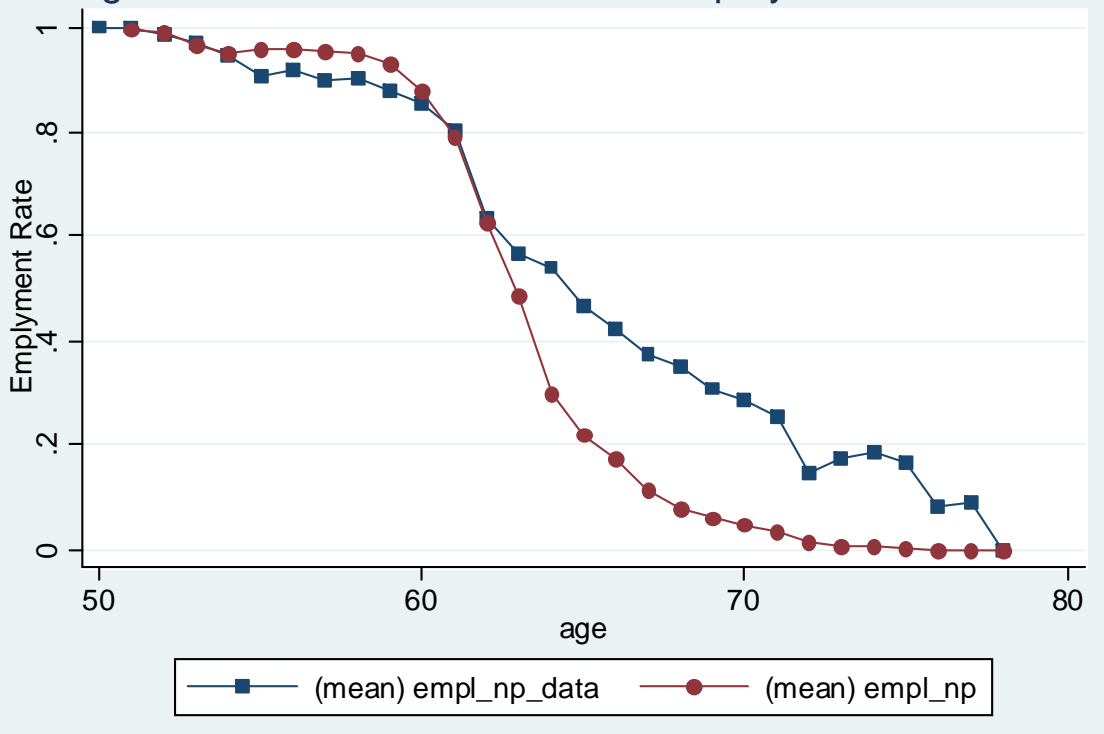

Figure A3: Simulated and Actual Employment Profiles: DC

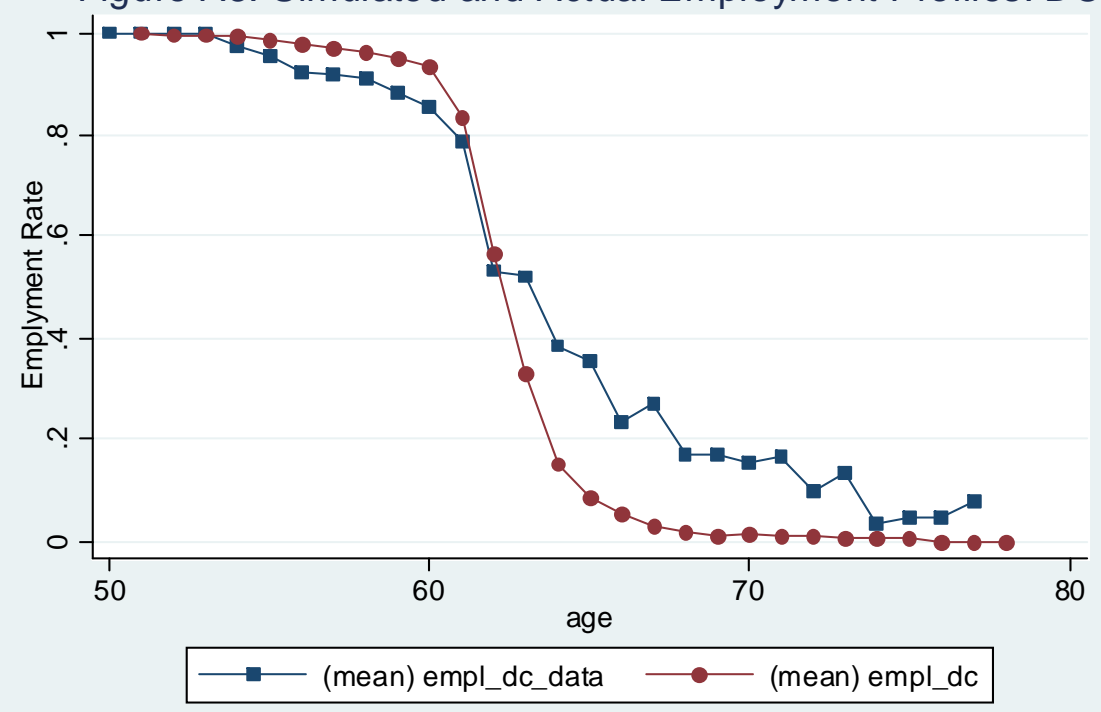

Figure A2: Simulated and Actual Employment Profiles: DB

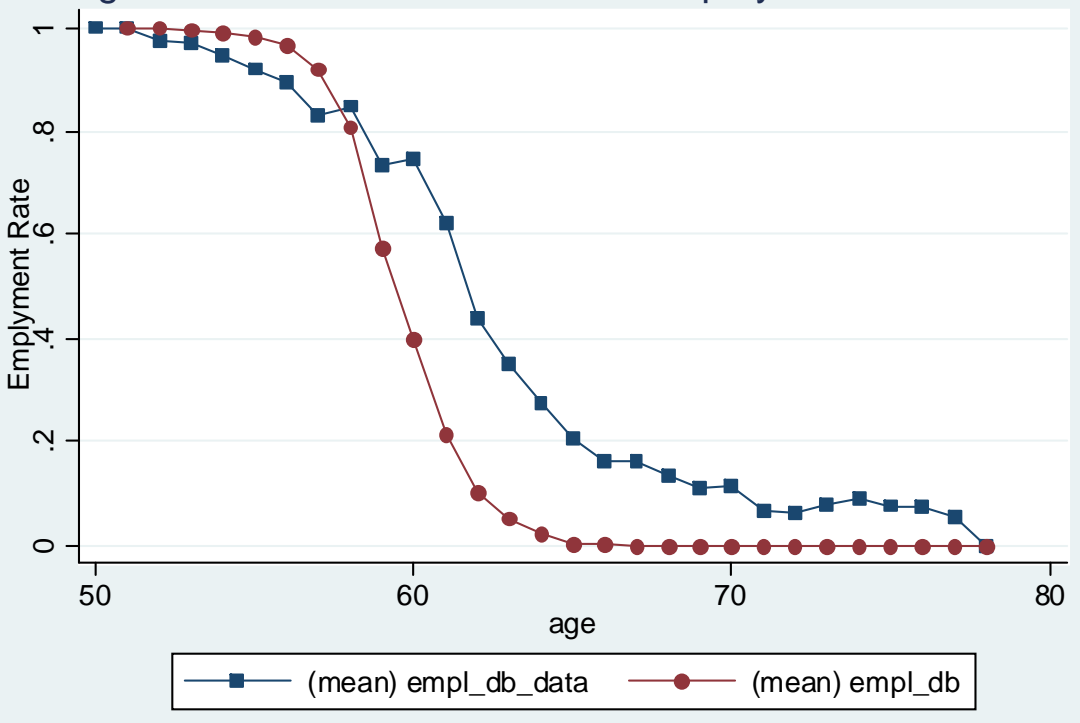

Appendix Figures: The data are for men born from 1931-1941 who worked full time in the 1992 HRS. They are followed through 2008. 